\title{
Do institutional changes affect business cycles? Evidence from Europe*
}

\author{
Fabio Canova \\ Matteo Ciccarelli \\ ICREA-UPF, BGSE, CREI, CREMeD and CEPR \\ European Central Bank \\ Eva Ortega ${ }^{\dagger}$ \\ Banco de España
}

April 2012

\begin{abstract}
We study the effects that the Maastricht treaty, the creation of the ECB, and the Euro changeover had on the dynamics of European business cycles using a panel VAR and data from ten European countries - seven from the Euro area and three outside of it. There are changes in the features of European business cycles and in the transmission of shocks. They precede the three events of interest and are more linked to a general process of European convergence and synchronization.
\end{abstract}

JEL classification: C15, C33, E32, E42

Key words: Business cycles, European Monetary Union, Panel VAR, Structural changes.

${ }^{*}$ We would like to thank the editor, C. Otrok, two anonymous referees, G. Amisano, D. Giannone, S. Eickmeier, G. Primiceri and the participants of a number of seminars and conferences for useful comments and suggestions. Canova acknowledges the financial support of the Spanish Ministry of Science and Technology, through the grant ECO2009-08556, and of the Barcelona Graduate School of Economics. This paper should not be reported as representing the views of the Banco de España, the European Central Bank, or the Eurosystem.

${ }^{\dagger}$ Corresponding author: Banco de España, Calle Alcala 48. 28014 Madrid Spain. Email: eortega@bde.es. 


\section{Introduction}

Many studies have shown that real activity in developed countries displays common characteristics, see Del Negro and Otrok (2008), Giannone and Reichlin (2006) and Canova et al. (2007) among others. There is also mounting evidence that the characteristics of real cyclical fluctuations are changing over time. For example, Bayoumi and Helbling (2003) find that synchronization of OECD cycles increased after 2000; Stock and Watson (2003) highlight changes in the volatility of G-7 cycles in the 1990s, and Canova et al. (2007) document variations in the correlation structure of G-7 fluctuations since the late 1980s.

Why are the cyclical features of industrialized economies changing? Three possibilities come to mind. It could be that variations in structural features have altered the transmission of shocks within and across countries. For instance, changes in the preferences of the monetary authority have been often invoked to explain the "Great inflation" of the 1970s and the subsequent period of a more stable and predictable macroeconomic environment in the US and other countries (see e.g. Lubik and Schorfheide, 2004, or Cogley and Sargent, 2005). An alternative possibility is that the characteristics and the frequency of the shocks hitting developed economies have dramatically changed. Sims and Zha (2006) and Canova and Gambetti (2009) among others, argued that changes in the volatility of macroeconomic shocks could be responsible for changes in the volatility and in the persistence of output and inflation in the US; Stock and Watson (2003) suggested that changes in the shock volatility affected the magnitude of the international correlation of macroeconomic variables; and Bayoumi and Helbling (2003) claimed that common shocks are now more frequent than used to be. Finally, institutional changes may have altered the nature of cyclical fluctuations. Thus, the same type of shocks and the same policies could have had different repercussions because the environment in which they took place has changed. To the best of our knowledge, this last option has received little attention in the literature. This seems an important shortcoming since, at least in Europe, the institutional setting has dramatically changed over the last 20 years - the Maastricht treaty implemented, the European Central Bank created, the Euro introduced. The recent sovereign debt crisis 
has created expectations of further institutional changes which may alter the transmission of shocks in Euro area countries, the propagation between Euro area and non-Euro area countries, and in general, the way business cycles shape.

Several reasons may explain why the literature has largely neglected the topic. Institutions typically change slowly making it difficult to select subsamples over which to compare cyclical fluctuations; variations of this type may affect cycles with much longer periodicity than the ones typically associated with business fluctuations (see e.g. earlier work by Alesina, 1988, or Ball, 2011); externalities and threshold effects may matter and long delays make their quantitative importance difficult to measure in small samples. Finally, institutional changes hardly come in a vacuum and this makes it particularly difficult to attribute observed variations to these factors.

This paper sheds some light on the issue by focusing on the consequences that the Maastricht treaty, the creation of the ECB and the Euro changeover had for European real cyclical fluctuations. The investigation is relevant from, at least, three different perspectives. First, since these changes were brought about by politicians and were, to a large extent, exogenous with respect to the dynamics of the European economies, the experience is unique to verify some well-known implications of the common currency area literature. For example, does real convergence precede the establishment of common monetary institutions or the reverse holds true? Second, two of the events are monetary in nature. The ability of monetary factors to affect real variables at business cycle frequencies has been extensively studied and limited effects typically found. However, the events we consider are different from those typically examined in the literature and their consequences a-priori comparable to the establishment of the Fed or the breakdown of the gold standard, which did affect cyclical fluctuations (see e.g. Bergman, et al., 1998). Third, in macroeconomic analyses it is common to separate business cycles from other types of fluctuations claiming that the mechanism generating the two types of movements is different. If institutional changes, besides affecting medium-long run tendencies, also exercise an impact on the business cycle, such a practice should be reconsidered.

Since the subject is largely unexplored, we focus attention to two somewhat narrow 
questions. Has there been any tendency for European and national cycles to vary when these institutional changes took place? Is there any difference in the relative impact that the institutional reforms had on the cyclical characteristics of the data?

To study these questions we employ a panel VAR model of the type developed in Canova and Ciccarelli (2009). The setup is useful because i) it handles large scale models displaying unit specific dynamics and cross country lagged interdependencies; ii) it flexibly allows for time variations in the correlation structure across variables and units; and iii) it features an index structure, where the distribution of European, Euro area and national specific cyclical indicators can recursively be constructed. Since our sample of countries includes both Euro area and non-Euro countries, we have a natural control group which helps us to strengthen our conclusions about the relevance of the creation of the ECB and the Euro changeover for European cyclical fluctuations.

The features of European and national cycles have changed over time. For instance, we detect volatility changes, variations in the persistence of the fluctuations of both European and national cycles, and a higher conformity between national and European fluctuations since 1990. Furthermore, there has been an intensification of the links, both within Europe, and between Europe and the US, and shocks are now 'more' common than in the past. However, these variations either predate or are disconnected with the events of interest, and are shared by Euro area and non-Euro area countries. In addition, our model predicts the pattern of output growth fluctuations well after the creation of the ECB and the Euro changeover, suggesting that these two events did not produce clean breaks in the dynamics of real variables. Thus, time variations in the features and the transmission of cyclical fluctuations appear to be linked more to the general process of European convergence taking place since the mid-1980s than to the institutional changes we consider.

While the evidence is not very supportive, one should be careful in drawing the conclusion that the institutional events have no effects on the real fluctuations. Our study examines only demeaned, standardized business cycles fluctuations; thus, effects on the level or the volatility could be present. Medium term (say, 8 and 12 years) cycles could also be influenced. Moreover, while not directly linked to business cycle variations, in- 
stitutional changes could have indirectly contributed to solidify on-going tendencies, for example, by making the environment more predictable or better insulating the real economy from undesirable nominal shocks. These issues are interesting but, to quantify their importance, a more structural model needs to be employed.

The rest of the paper is organized as follows: the next section presents the model, the technique used to construct the indicators and interesting statistics. Section 3 presents the data and some specification analysis. Section 4 contains the results. Section 5 concludes.

\section{The empirical model}

The empirical model we employ has the form:

$$
y_{i t}=D_{i t}(L) Y_{t-1}+F_{i t}(L) W_{t}+e_{i t}
$$

where $i=1, \ldots, N$ refers to countries and $t=1, \ldots, T$ to time; $y_{i t}$ is a $G \times 1$ vector for each $i, Y_{t}=\left(y_{1 t}^{\prime}, y_{2 t}^{\prime}, \ldots y_{N t}^{\prime}\right)^{\prime} ; D_{i t, j}$ are $G \times N G$ matrices for each lag $j=1, \ldots, p, W_{t}$ is a $M \times 1$ vector of exogenous variables, $F_{i t, j}$ are $G \times M$ matrices each lag $j=0,1, \ldots, q-1$, and $e_{i t}$ is a $G \times 1$ vector of random disturbances.

The model displays three important ingredients which makes it ideal for our purposes. First, coefficients are allowed to vary over time. Without this feature, smooth changes in business cycle features could be mistakenly attributed to the once-and-for-all institutional changes we are concerned with. Second, the dynamic relationships are allowed to be unit specific. Without such a flexibility, heterogeneity biases may be present, and economic conclusions could be easily distorted. Third, whenever the $N G \times N G$ matrix $D_{t}(L)=\left[D_{1 t}(L), \ldots, D_{N t}(L)\right]^{\prime}$, is not block diagonal for some $L$, cross-unit lagged interdependencies matter. Thus, dynamic feedbacks across units are allowed for and this greatly expands the type of interactions the model can account for.

While these ingredients add realism to the specification and avoid the short-cuts that the literature has often taken (see Canova and Ciccarelli, 2009, for discussion), they are not costless: the number of parameters is large (there are $k=N G p+M q$ parameters in each equation) and there is only one time period per unit to estimate them. For estimation 
purposes, it is convenient to rewrite (1) in a simultaneous equations format:

$$
Y_{t}=Z_{t} \delta_{t}+E_{t}
$$

where $Z_{t}=I_{N G} \otimes X_{t}^{\prime} ; X_{t}^{\prime}=\left(Y_{t-1}^{\prime}, Y_{t-2}^{\prime}, \ldots, Y_{t-p}^{\prime}, W_{t}^{\prime}, W_{t-1}^{\prime}, \ldots, W_{t-q}^{\prime}\right), \delta_{t}=\left(\delta_{1 t}^{\prime}, \ldots, \delta_{N t}^{\prime}\right)^{\prime}$ and $\delta_{i t}$ are $G k \times 1$ vectors containing, stacked, the $G$ rows of the matrix $D_{i t}$ and $F_{i t}$, while $Y_{t}$ and $E_{t}$ are $N G \times 1$ vectors. Since $\delta_{t}$ varies with cross-sectional units in different time periods, it is impossible to estimate it using unrestricted classical methods. However, even if $\delta_{t}$ were time invariant, its sheer dimensionality prevents any meaningful unconstrained estimation. To overcome this problem we assume that $\delta_{t}$ depends on a much lower dimension vector $\theta_{t}$ and posit the following linear structure:

$$
\delta_{t}=\Xi_{1} \theta_{1 t}+\Xi_{2} \theta_{2 t}+\Xi_{3} \theta_{3 t}+\Xi_{4} \theta_{4 t}+u_{t}
$$

where $\Xi_{1}, \Xi_{2}, \Xi_{3}, \Xi_{4}$ are matrices of dimensions $N G k \times s, N G k \times N, N G k \times G, N G k \times 1$ respectively and $\theta_{i t}, i=1, \ldots, 4$ are mutually orthogonal. Here $\theta_{1 t}$ captures movements in the coefficient vector which are common across countries and variables (or groups of them) and is of dimension $s ; \theta_{2 t}$ captures movements in the coefficient vector which are common within countries and its dimension equals to $N ; \theta_{3 t}$ captures movements in the coefficient vector which are variable specific and its dimension is equal to $G ; \theta_{4 t}$ is a scalar process which captures movements in the coefficients due to the $M$ exogenous variables. Finally, $u_{t}$ captures all the unmodeled features of the coefficient vector, which may have to do with lag specific, time specific or other idiosyncratic effects.

Factoring $\delta_{t}$ as in (3) is advantageous in many respects. Computationally, it reduces the problem of estimating $N G k$ coefficients into the one of estimating $s+N+G+1$ factors characterizing their dynamics. Practically, the factorization (3) transforms an overparameterized panel VAR into a parsimonious SUR model, where the regressors are averages of certain right-hand side VAR variables. In fact, using (3) in (2) we have

$$
Y_{t}=\sum_{i=1}^{4} \mathcal{Z}_{i t} \theta_{i t}+v_{t}
$$

where $\mathcal{Z}_{i t}=Z_{t} \Xi_{i}$ capture respectively, common, country specific, variable specific and exogenous specific information present in the data, and $v_{t}=E_{t}+Z_{t} u_{t}$. Economically, 
the decomposition in (4) conveniently allows us to measure the relative importance of common and country specific influences for fluctuations in $Y_{t}$ and thus to examine whether institutional events affect them differently. In fact, $W L I_{t}=\mathcal{Z}_{1 t} \theta_{1 t}$ plays the role of a common indicator, while $C L I_{t}=\mathcal{Z}_{2 t} \theta_{2 t}$ plays the role of a vector of country specific indicators. Note that $W L I_{t}$ and $C L I_{t}$ are correlated - a portion of the variables in $\mathcal{Z}_{1 t}$ also enter in $\mathcal{Z}_{2 t}$ - but the correlation tends to zero as $N$ increases.

To illustrate the structure of the $\mathcal{Z}_{j t}$ 's suppose there are $G=2$ variables, $N=2$ countries, $s=1$ common component, $p=1$ lags, and $M=0$ exogenous variables. Then:

$$
\left[\begin{array}{c}
y_{t}^{1} \\
x_{t}^{1} \\
y_{t}^{2} \\
x_{t}^{2}
\end{array}\right]=\left[\begin{array}{llll}
d_{1,1, t}^{1, y} & d_{2,1, t}^{1, y} & d_{1,2, t}^{1, y} & d_{2,2, t}^{1, y} \\
d_{1,1, t}^{1, x} & d_{2,1, t,}^{1, x} & d_{1,2, t}^{1, x} & d_{2,2, t}^{1, x} \\
d_{1, y, t}^{2, y} & d_{2, y, t}^{2, y} & d_{1,2, t}^{2, y} & d_{2,2, t}^{2, y} \\
d_{1,1, t}^{2, x} & d_{2,1, t}^{2, x} & d_{1,2, t}^{2, x} & d_{2,2, t}^{2, x}
\end{array}\right]\left[\begin{array}{c}
y_{t-1}^{1} \\
x_{t-1}^{1} \\
y_{t-1}^{2} \\
x_{t-1}^{2}
\end{array}\right]+e_{t}
$$

Thus $\delta_{t}=\left[d_{1,1, t}^{1, y}, d_{2,1, t}^{1, y}, d_{1,2, t}^{1, y}, d_{2,2, t}^{1, y}, d_{1,1, t}^{1, x}, d_{2,1, t}^{1, x}, d_{1,2, t}^{1, x}, d_{2,2, t}^{1, x}, d_{1,1, t}^{2, y}, d_{2,1, t}^{2, y}, d_{1,2, t}^{2, y}, d_{2,2, t}^{2, y}\right.$, $\left.d_{1,1, t}^{2, x}, d_{2,1, t}^{2, x}, d_{1,2, t}^{2, x}, d_{2,2, t}^{2, x},\right]^{\prime}$ is a $16 \times 1$ vector and the typical element of $\delta_{t}, \delta_{l, s, t}^{i, j}$, is indexed by the country $i$, the variable $j$, the variable in an equation $l$ (independent of the country), and the country in an equation $s$ (independent of variable). If we are not interested in modelling all these aspects, one possible factorization of $\delta_{t}$ is

$$
\delta_{t}=\Xi_{1} \theta_{1 t}+\Xi_{2} \theta_{2 t}+\Xi_{3} \theta_{3 t}+u_{t}
$$

where $u_{t}$ captures unaccounted features, and for each $t, \theta_{1 t}$ is a scalar, $\theta_{2 t}$ is a $2 \times 1$ vector, $\theta_{3 t}$ is a $2 \times 1$ vector, $\Xi_{1}$ is a $16 \times 1$ vector of ones,

$$
\underset{(16 \times 2)}{\Xi_{2}}=\left[\begin{array}{cc}
\iota_{1} & 0 \\
\iota_{1} & 0 \\
0 & \iota_{2} \\
0 & \iota_{2}
\end{array}\right] \quad \underset{(16 \times 2)}{\Xi_{3}}=\left[\begin{array}{cc}
\varkappa_{1} & 0 \\
0 & \varkappa_{2} \\
\varkappa_{1} & 0 \\
0 & \varkappa_{2}
\end{array}\right]
$$

with $\iota_{1}=\left(\begin{array}{cccc}1 & 1 & 0 & 0\end{array}\right)^{\prime}, \iota_{2}=\left(\begin{array}{llll}0 & 0 & 1 & 1\end{array}\right)^{\prime}, \varkappa_{1}=\left(\begin{array}{cccc}1 & 0 & 1 & 0\end{array}\right)^{\prime}$ and $\varkappa_{2}=\left(\begin{array}{cccc}0 & 1 & 0 & 1\end{array}\right)^{\prime}$.

Hence, the VAR in (5) can be rewritten as

$$
\left[\begin{array}{c}
y_{t}^{1} \\
x_{t}^{1} \\
y_{t}^{2} \\
x_{t}^{2}
\end{array}\right]=\left[\begin{array}{c}
\mathcal{Z}_{1 t} \\
\mathcal{Z}_{1 t} \\
\mathcal{Z}_{1 t} \\
\mathcal{Z}_{1 t}
\end{array}\right] \theta_{1 t}+\left[\begin{array}{cc}
\mathcal{Z}_{2,1, t} & 0 \\
\mathcal{Z}_{2,1, t} & 0 \\
0 & \mathcal{Z}_{2,2, t} \\
0 & \mathcal{Z}_{2,2, t}
\end{array}\right] \theta_{2 t}+\left[\begin{array}{cc}
\mathcal{Z}_{3,1, t} & 0 \\
0 & \mathcal{Z}_{3,2, t} \\
\mathcal{Z}_{3,1, t} & 0 \\
0 & \mathcal{Z}_{3,2, t}
\end{array}\right] \theta_{3 t}+v_{t}
$$


where $\mathcal{Z}_{1 t}=y_{t-1}^{1}+x_{t-1}^{1}+y_{t-1}^{2}+x_{t-1}^{2}+1, \mathcal{Z}_{2,1, t}=y_{t-1}^{1}+x_{t-1}^{1}, \mathcal{Z}_{2,2, t}=y_{t-1}^{2}+x_{t-1}^{2}$, $\mathcal{Z}_{3,1, t}=y_{t-1}^{1}+y_{t-1}^{2}, \mathcal{Z}_{3,2, t}=x_{t-1}^{1}+x_{t-1}^{2}$ and $v_{t}=e_{t}+Z_{t}^{\prime} u_{t}$.

As the notation used makes it clear, the regressors in (4) are combinations of lags of the right hand side variables of the VAR, while $\theta_{i t}$ are time varying loadings. Using averages as regressors is common in the factor model literature (see e.g. Stock and Watson, 1989, or Forni and Reichlin, 1998) and in the signal extraction literature (see e.g. Sargent, 1989). Two important differences between (4) and standard factor models need to be noted. First, the indicators equally weight the information in all variables. The equal weighting scheme comes directly from (3) and the fact that all variables are measured in the same units (all variables will be demeaned and standardized). Second, our indices are observable and dynamically span lagged interdependencies across countries and variables.

\subsection{The complete model}

To complete the specification we need additional assumptions. First, we assume that $E_{t} \sim N(0, \Omega)$. Thus, we do not allow for time variations in the variance of the shocks of the original panel VAR. Nevertheless, as it will be clear below, our model can capture volatility changes in the reduced form disturbances. Second, we assume that $u_{t} \sim N(0, \Omega \otimes V)$ where $V$ is a $k \times k$ matrix. Third, letting $\theta_{t}=\left[\theta_{1 t}, \ldots, \theta_{4 t}\right]^{\prime}$ we specify

$$
\theta_{t}=\theta_{t-1}+\eta_{t} \quad \eta_{t} \sim N\left(0, B_{t}\right)
$$

where $B_{t}$ is block diagonal and let $E_{t}, u_{t}$ and $\eta_{t}$ be mutually independent.

In (8) the factors evolve over time as random walks. This assumption is common in the time varying coefficient VAR literature (see e.g. Canova and Gambetti, 2009), is parsimonious and typically preferred to more complicated structure in forecasting sense and allows us to focus on coefficient changes which are permanent. The variance of $\eta_{t}$ is allowed to be time varying to account for ARCH-M type effects and other generic volatility clustering that may appear in $Y_{t}$. The block diagonality of $B_{t}$ guarantees orthogonality of the factors, which is preserved a-posteriori, and hence their identifiability. Finally, both 
the choice of making the errors independent and the covariance matrix of $u_{t}$ proportional to $\Omega$ are standard in hierarchical models (see e.g. Kadiyala and Karlsson, 1997).

Two other comments are in order. First, we parameterize $V=\sigma^{2} I_{k}$ to reflect the fact that the factors have similar units and use $\sigma^{2}$ to optimize the setup. Second, we allow for time variations in the variance of $\eta_{t}$, rather than in the variance of $E_{t}$, because computational costs are reduced (in our application, $B_{t}$ is just a $4 \times 1$ vector rather than a $60 \times 1$ vector). We set $B_{t}=\gamma_{1} * B_{t-1}+\gamma_{2} * \bar{B}$, and search for values of $\gamma_{1}, \gamma_{2}$ to maximize the fit of the model. Thus, while we will use Bayesian methods to construct posterior distributions of the quantity of interest, we reduce the complexity of problem by treating some parameters as fixed, as in empirical Bayes analysis, and optimize them using ML-type II methods (see e.g. Canova, 2007). It turns out that the optimal value of $\gamma_{1}$ is very small, making $B_{t}$ effectively constant.

\subsection{Priors and Posteriors}

To compute posterior distributions, we assume prior densities for $\phi_{0}=\left(\Omega^{-1}, \bar{B}, \theta_{0}\right)$. We set $\bar{B}_{i}=b_{i} * I, i=1, \ldots, 4$, where $b_{i}$ controls the tightness of factor $i$ in the coefficients, and make $p\left(\Omega^{-1}, b_{i}, \theta_{0}\right)=p\left(\Omega^{-1}\right) \prod_{i} p\left(b_{i}\right) p\left(\theta_{0}\right)$ with $p\left(\Omega^{-1}\right)=W\left(z_{1}, Q_{1}\right)$, $p\left(b_{i}\right)=I G\left(\frac{\varpi_{0}}{2}, \frac{S_{0}}{2}\right)$ and $p\left(\theta_{0} \mid \mathcal{F}_{-1}\right)=N\left(\bar{\theta}_{0}, \overline{\mathrm{R}}_{0}\right)$ where $N$ stands for Normal, $W$ for Wishart and $I G$ for Inverse Gamma distributions, and $\mathcal{F}_{-1}$ denotes the information available at time -1 . The prior for $\theta_{0}$ and the law of motion for the factors imply that $p\left(\theta_{t} \mid \mathcal{F}_{t-1}\right)=N\left(\bar{\theta}_{t-1 \mid t-1}, \overline{\mathrm{R}}_{t-1 \mid t-1}+B_{t}\right)$.

We collect the hyperparameters of the prior in the vector $\mu=\left(z_{1}, Q_{1}, \varpi_{0}, S_{0}, \bar{\theta}_{0}, \overline{\mathrm{R}}_{0}\right)$. Values for the elements of $\mu$ are either obtained from the data (this is the case for $\bar{\theta}_{0}, Q_{1}$ ) to tune up the prior to the application or a-priori selected to produce relatively loose priors (this is the case for $z_{1}, \varpi_{0}, S_{0}, \overline{\mathrm{R}}_{0}$ ). The values used are: $z_{1}=N \cdot G+5, Q_{1}=$ $\hat{Q}_{1}, \varpi_{0}=10^{6}, S_{0}=1.0, \bar{\theta}_{0}=\hat{\theta}_{0}$ and $\overline{\mathrm{R}}_{0}=I_{4}$. Here $\hat{Q}_{1}$ is a block diagonal matrix $\hat{Q}_{1}=\operatorname{diag}\left(Q_{11}, \ldots, Q_{1 N}\right)$ and $Q_{1 i}$ is the estimated covariance matrix of the time invariant version for country $i$ VAR; $\hat{\theta}_{0}$ is obtained with an OLS regression on a time invariant version of (1) over the entire sample. Note that by setting $\varpi_{0}=10^{6}$ we impose a tight 
prior on time variation. We test this specification against a looser alternative in section 3.

To calculate the posterior distribution for $\phi=\left(\Omega^{-1}, b_{i},\left\{\theta_{t}\right\}_{t=1}^{T}\right)$, we combine the prior with the likelihood of the data, which is proportional to

$$
L \propto|\Omega|^{-T / 2} \exp \left[-\frac{1}{2} \sum_{t}\left(Y_{t}-Z_{t} \Xi \theta_{t}\right)^{\prime} \Omega^{-1}\left(Y_{t}-Z_{t} \Xi \theta_{t}\right)\right]
$$

where $Y^{T}=\left(Y_{1}, \ldots, Y_{T}\right)$ denotes the data. Using Bayes rule, $p\left(\phi \mid Y^{T}\right)=\frac{p(\phi) L\left(Y^{T} \mid \phi\right)}{p\left(Y^{T}\right)} \propto$ $p(\phi) L\left(Y^{T} \mid \phi\right)$. Once these distributions are found, location and dispersion measures for any interesting continuous functions $h(\theta)$ can be obtained.

Since it is impossible to compute $p\left(\phi \mid Y^{T}\right)$ analytically, a Gibbs sampler is used to draw sequences from the posterior. Denoting $\phi_{-\kappa}$ the vector $\phi$ excluding the parameter $\kappa$, the conditional distributions needed in the Gibbs sampler are

$$
\begin{aligned}
\theta_{t} \mid Y^{T}, \phi_{-\theta_{t}} & \sim N\left(\bar{\theta}_{t \mid T}, \overline{\mathrm{R}}_{t \mid T}\right) \quad t \leq T, \\
\Omega^{-1} \mid Y^{T}, \phi_{-\Omega} & \sim W i\left(z_{1}+T,\left[, \sum_{t}\left(Y_{t}-Z_{t} \Xi \theta_{t}\right)\left(Y_{t}-Z_{t} \Xi \theta_{t}\right)^{\prime}+Q_{1}^{-1}\right]^{-1}\right) \\
b_{i} \mid Y^{T}, \phi_{-b_{i}} & \sim I G\left(\frac{\varpi^{i}}{2}, \frac{\sum_{t}\left(\theta_{t}^{i}-\theta_{t-1}^{i}\right)^{\prime}\left(\theta_{t}^{i}-\theta_{t-1}^{i}\right)+S_{0}}{2}\right)
\end{aligned}
$$

where $\bar{\theta}_{t \mid T}$ and $\overline{\mathrm{R}}_{t \mid T}$ are the smoothed one-period ahead forecasts of $\theta_{t}$ and of the variancecovariance matrix of the forecast error calculated as in Chib and Greenberg (1995), $\varpi^{i}=$ $K+\varpi_{0}$, and $K=T s$, if $i=1, K=T g$, if $i=2, K=T N$, if $i=3, K=T$, if $i=4$.

Under regularity conditions (see Geweke, 2000), cycling through the distributions in (10) produces in the limit draws from the joint posterior of interest. From these, the marginal distributions of $\theta_{t}$ can be computed averaging over draws in the nuisance dimensions and, as a by-product, the posterior distributions of our indicators can be obtained. For example, a credible $90 \%$ interval for the common indicator is obtained ordering the draws of $W L I_{t}^{h}$ for each $t$ and taking the 5 th and the 95 th percentile of the distribution. We have performed standard convergence checks: increasing the length of the chain; splitting the chains in pieces after a burn-in period and calculating whether the mean and the variances are similar; checking if cumulative means settle to some value. The results we present are 
based on 150000 draws: 3000 blocks of 50 draws were made and the last draw for each block is retained. Of these, 2000 draws are used for posterior inference at each $t$.

\subsection{Summary Statistics}

Besides characterizing the time profile of the posterior distribution of interesting cyclical indicators, we will be interested in computing predictive distributions for $Y_{t+\tau}, \tau=1,2$, $\ldots$, which is given by $f\left(Y_{t+\tau}\right)=\int f\left(Y_{t+\tau} \mid Y_{t}, \phi_{t+\tau}\right) g\left(\phi_{t+\tau} \mid Y_{t}\right) d \phi_{t+\tau}$, and $t$ varies. These distributions can be obtained numerically using the structure of the model and draws for the posterior of the parameters and/or the shocks. To draw from this predictive densities, we condition on $\theta_{t+\tau}=\theta_{t}$.

We will also be interested in computing the dynamic response of the endogenous variables to shocks in different samples. Since the model is intrinsically non-linear, we compute responses as the difference between two conditional forecasts: one where a particular variable (or set of variables) is shocked and one where the disturbance is set to zero. Formally, let $y^{t}$ be a history for $y_{t} ; \theta^{t}$ be a trajectory for the coefficients up to $t, y_{t+1}^{t+\tau}=\left[y_{t+1}^{\prime}, \ldots y_{t+\tau}^{\prime}\right]^{\prime}$ a collection of future observations and $\theta_{t+1}^{t+\tau}=\left[\theta_{t+1}^{\prime}, \ldots \theta_{t+\tau}^{\prime}\right]^{\prime}$ a collection of future trajectories for $\theta_{t}$. Let $\theta_{t+\tau}=\theta_{t}, \mathcal{W}_{t}=\left(\Omega, B_{t}\right)$; set $\xi_{t}^{\prime}=\left[v_{1 t}^{\prime}, v_{2 t}^{\prime}, \eta_{t}^{\prime}\right]$, where $v_{1 t}$ are the shocks to the endogenous variables and $v_{2 t}$ the shocks to exogenous variables. Let $\xi_{j, t+1}^{\delta}$ be a realization of $\xi_{j, t+1}$ of size $\delta$ and $\mathcal{F}_{t}^{1}=\left\{y^{t}, \theta^{t}, \mathcal{W}_{t}, J_{t}, \xi_{j, t}^{\delta}, \xi_{-j, t}, \xi_{t+1}^{t+\tau}\right\}$ and $\mathcal{F}_{t}^{2}=\left\{y^{t}, \theta^{t}, \mathcal{W}_{t}, J_{t}, \xi_{t}, \xi_{t+1}^{t+\tau}\right\}$ be two conditioning sets, where $\xi_{-j, t}$ indicates all shocks, excluding the one in the j-th component and $J_{t}$ is an identification matrix satisfying $J_{t} J_{t}^{\prime}=\Omega$. Then, responses at horizon $\tau$ to an impulse in $\xi_{j, t}^{\delta}, j=1, \ldots$ are

$$
I R_{y}^{j}(t, \tau)=E\left(y_{t+\tau} \mid \mathcal{F}_{t}^{1}\right)-E\left(y_{t+\tau} \mid \mathcal{F}_{t}^{2}\right) \quad \tau=1,2, \ldots
$$

When the coefficients are constant, (11) collapses to the traditional impulse response function to unitary structural shocks. 


\section{The data}

The endogenous variables of the model are demeaned and standardized year-on-year growth rates of output, industrial production, employment, consumption, investment and prices for Germany, France, Italy, Spain, Belgium, Netherlands, Finland, the UK, Denmark and Sweden for the period 1970Q1 to 2010Q4. Since the sample includes seven Euro Area economies and the three most relevant countries which declined joining the zone, we treat the latter as a control group in assessing the relevance and the scope of creation of the ECB and the Euro changeover. Ideally, we would like to have a larger number of variables in the model. Computational complexities and lack of availability of comparable variables across countries for the full sample period limit the size of the system we consider. We follow the practice of dating committees in both the US (NBER) and Europe (CEPR) and simultaneously use output, industrial production, employment, consumption and investment in constructing our real indicators. Although the investigation is concerned with real cycles, we use CPI inflation to control for nominal factors and their feedback to real variables, which could be potentially important to accurately measure the effects of the monetary events of interest. The intensification of trade links over time is captured by an exogenous variable since this trend is shared by all countries in the world.

Industrial production is measured by its index, employment by the total employment index and prices by the CPI index, all of which are from OECD Main Economic Indicators. Output is measured by real GDP, consumption by total real private consumption expenditure and investment by real gross fixed capital formation. These three variables are in 2000 prices and are from the OECD Economic Outlook database.

Variables are demeaned prior to the estimation since we are interested in fluctuations around some pivotal point rather than raw growth rates. While we demean by sample averages, the results we present are broadly unchanged if a recursive mean is eliminated from the variables. We standardize the variables, as in a factor model, so that variables with higher volatility will not abnormally matter in constructing the indicators of interest. Finally, year-on-year growth rates are selected as they are less affected than annualized 
quarter-on-quarter growth rates by temporary and idiosyncratic variations.

The exogenous variables we use are the growth rates of oil prices, of the world trade, of US GDP, and the US nominal interest rate. Oil prices are quarterly average of daily prices and come from the IMF International Financial Statistics; world trade is measured by the total volume of world trade in goods and services in 2000 prices and is from the OECD Main Economic Indicators. US GDP comes from the Bureau of Economic Analysis - despite being reported as seasonally adjusted at the source, residual seasonality was present and eliminated with TRAMO-SEATS. The US interest rate is the 3-month nominal interbank rate and is obtained from the OECD Main Economic Indicators. We use one lag of both the endogenous and exogenous variables. Hence, there are 60 equations and the system has $60 \times(60 \times 1+4 \times 1)=3840$ coefficients.

The sample is long enough to perform a number of statistical exercises to confirm that our statistical model is sufficiently well specified. The relatively long sample size also allows us to check whether statistical breaks in the properties of the series used in the estimation exist and whether they occur in correspondence with the dates of institutional changes. Unfortunately, as documented in the on-line appendix, standard break tests are non-informative on this issue. While most series appear to display structural breaks in their moments or their dynamic profile, different series within the same country display breaks at different dates, breaks are heterogeneously distributed across countries over time, and do not appear to cluster around the dates when the institutional changes took place. Thus, we use history and hindsight to choose the dates around which to focus our analysis.

The Maastricht Treaty was signed on February 7, 1992, but became effective only on November 1st, 1993. Since there was considerable uncertainty regarding the actual implementation of the treaty, we take 1993Q3 as our (conservative) cut-off point. The ECB creation occurred on June 1st, 1998, and the cut-off point is 1998Q3. Finally, the Euro changeover occurred on January 1, 2002 and thus the cut-off point is 2002Q1. Moving backward or forward the cut-off date by one year (or up to 1992Q1 in the case of the Maastricht Treaty) does not affect any of the conclusions we present. 


\subsection{Some preliminary analysis}

Before analyzing the questions of interest, it is useful to address some preliminary issues concerning the specification of the model. The credibility of our conclusions will be enhanced if the model fits the data well relative to alternatives, if the choice of continuous time variations is supported in the data, and if our cyclical indicators reproduce important features of the data. The model used in the next section was selected with a specification search and different models were compared using the marginal likelihood (ML) criteria. The marginal likelihood of model $M_{i}$ is $f\left(Y \mid M_{i}\right)=\int L\left(y \mid \phi_{i}, M_{i}\right) g\left(\phi_{i} \mid M_{i}\right) d \phi_{i}$, where $\phi_{i}$ is the vector of the parameters of $M_{i} . M_{i}$ is preferable to $M_{i^{\prime}}$ if the log Bayes factor $B F\left(M_{i}, M_{i^{\prime}}\right)=\log \frac{f\left(Y \mid M_{i}\right)}{f\left(Y \mid M_{i^{\prime}}\right)}$ substantially exceeds 10 .

The benchmark specification, which features little (prior) time variation, unit-specific dynamics, one common real factor, one common nominal factor, and specific factors for the country, variable and exogenous components, has a log marginal likelihood (log ML $=$ -5188) which is higher than all the alternatives we considered. For example, a model with one single common factor, pooling real and nominal variables, has $\log \mathrm{ML}=-5221$; a model with higher prior time variation has $\log \mathrm{ML}=-5340$; a model with no country-specific dynamics has $\log \mathrm{ML}=-5378$; a model with no variable-specific effects has $\log \mathrm{ML}=$ -5496; a model where there is no exogenous factor and the coefficients on the exogenous variables receive no special treatment has $\log \mathrm{ML}=-5498$.

We have also examined whether it is useful to separate Euro specific from non-Euro specific real cycles in the common component. If the creation of the ECB or the Euro changeover mattered differently for the two groups of countries, the data is likely to prefer a specification where the two types of real cycles are distinct. It turns out that a model with two separate sets of common real factors has a $\log M L=-5209$. Thus, our benchmark specification is greatly preferred with $\log$ Bayes factor of 21 . To understand why the statistical results are so decisively in favour of one common real factor, figure 1 plots the posterior 68 percent tunnel for the common real indicator $\mathcal{Z}_{11 t} \theta_{11 t}$ (labelled 'common all'), together with the posterior median of the Euro and non-Euro real indicators $\mathcal{Z}_{11 t}^{E U} \theta_{11 t}^{E U}$ and $\mathcal{Z}_{11 t}^{\text {nonEU }} \theta_{11 t}^{\text {nonEU }}$ (labelled 'common $E M U$ ' and 'common non-EMU,' 
respectively). Clearly, the fluctuations in the two indicators are similar, highly in phase, and very much synchronized with those present in the common indicator. Fluctuations in the Euro indicator are less volatile than those in the non-Euro indicator up to the 1980s and more volatile around 1990, but apart from these two periods differences are minor. Thus, information is lost if the two areas are separated and this is reflected in the fact that the common real indicator is less volatile than each of two real regional indicators.

We have also examined whether our choice of continuous time variations in the coefficients characterizes the data better than one which has time variations just around the dates when institutional changes took place. The log ML of the second model is -5237 . Thus, our benchmark specification is significantly preferred with log Bayes factor of 49. To give a sense for why our continuous time varying specification is preferred, we have plotted in figure 2 rolling estimates of standard deviation, $\mathrm{AR}(1)$ coefficient, contemporaneous and maximum correlation for GDP and investment growth. Clearly, the idea that cyclical fluctuations were stable except at the points where institutional breaks took place is not supported in the data: time variations are continuous and generalized.

All in all, the model seems appropriate for the type of exercises we want to conduct and statistically superior to the reasonable alternatives we have considered.

\section{The results}

To examine whether the institutional changes affected the properties of European real cycles, we perform three exercises. First, we informally examine the dynamics of the estimated common and country specific indicators and compute reduced form statistics around the dates of the events. Second, we conduct a forecasting exercise to detect whether the institutional changes altered the pattern of cyclical fluctuations above those that would have been predictable using our time varying structure. Third, we compare the dynamic responses of certain endogenous variables to two interesting shocks using the information available before and after each of the events. These three exercises provide complementary information on the issues of interest since they look at in-sample reduced form statistics, out-of-sample profiles at interesting dates (in the same spirit as case studies), and in- 
sample conditional forecasting exercises. For future references, shaded areas in the figures capture recessions according to the CEPR classification (see www.cepr.org). Shaded areas in the plots of national indicators, on the other hand, represent official recessions phases as reported by the Economic Cycle Research Institute (ECRI)(www.businesscyle.com); these are absent from the plots for the Netherlands, Belgium, Denmark and Finland since no official dating is available.

\subsection{Some descriptive analysis}

Our estimated indicators capture important features of European and national business cycles. For example, figure 1 shows that the time path of the (common) real indicator shares important similarities with the synthetic Euro area GDP growth series, taken from the ECB Area Wide Model database. They are highly contemporaneously correlated (the maximum correlation is the contemporaneous one, with a coefficient of 0.77 ) and show similar serial correlation (around 0.9 in both cases). Euro area GDP is more volatile and slightly leads our European real indicator in the last two decades but, by and large, they have similar dynamic features - see on-line appendices for details.

The European common indicator of real activity has four strong recessions (1973-75, 1979-81, 1992-93, 2007-09) and a milder one (2001-2003). These dates are obtained feeding the median estimate into a Bry and Boschan algorithm, and correspond almost exactly to those reported by the CEPR. The business cycle phases of the national indicators shown in figure 3 are also well synchronized with those reported by ECRI. In fact, if we allow for one quarter (two quarters) of maximum discrepancy, the average coincidence between our dating and the ECRI dating is 63 (74) per cent.

The estimated European real indicator is characterized by different phases. Until the mid-1980s, fluctuations were volatile and the series crossed the zero line often. Afterwards, they were reduced, particularly after the early 1990s crisis. This low volatility phase ended abruptly in 2008 and the ensuing recession is the largest in the sample. Thus, while a "European cycle" is present throughout the period, it is only since the mid-1980s that it acquires typical persistence and duration features. The estimated national indicators (see 
figure 3), instead, display typical cyclical features throughout the sample. As intuition would suggest, these indicators are quite heterogeneous in terms of timing, amplitude and duration of the fluctuations. However, the characteristics of indicators of major countries become more similar as time goes by, and in the last recession, their coincidence reached a historical maximum. The ups and downs in the national indicators also become more correlated with those of the common real indicator as time progresses.

As figure 4 shows, recursive estimates of the volatilities of the European and the national indicators fall in the late 1980s, and there is some rebounding in the early 1990s (due to German reunification, the financial crises in the Nordic countries and the European Monetary System crisis). The fall becomes more marked up to 2008, when volatilities reached unprecedented levels. The initial declining trend is in line with the reduction in the real business cycle volatility documented, e.g., in Stock and Watson (2003). However, rather than happening in the early 1980s, the volatility reduction takes place in the late 1980s and in the 2000s and is therefore distinct from the Great Moderation phenomena. Since this is the period when inflation returned to low levels, this evidence suggests a generic process of cyclical convergence for the whole of Europe.

Despite these variations, the length of business cycles phases in both the real common and the national indicators is roughly invariant over time. For example, recessions in the European real indicator last on average 7 quarters. The length of recessions in the national indicators is somewhat heterogeneous, is on average of 6 quarters while individual country averages range from 5 to 8 quarters.

The time variations we highlighted square reasonably well with what is known in the literature. For example, in line with Canova et al. (2007), the strengthening of a common cyclical pattern does not imply that national cycles are disappearing. In fact, the stronger cyclicality displayed by the European real indicator is not the result of an increase in the synchronization across countries - the maximum correlation between the European and the national indicators was almost always contemporaneous (see figure 4). Instead, it comes from more intense comovements across countries - the contemporaneous correlation of almost all national indicators with the European indicator increases over time. 


\subsection{Institutional changes and real fluctuations}

Artis and Zhang (1997) analyzed business cycles statistics in Europe for the period up to 1979 and for the 1979-91 period - the period of the first European Monetary System (EMS). They found an increase in the degree of conformity and of synchronization in the fluctuations of the countries participating to the first monetary system, an increase which was not present in non-EMS countries. Figure 4 seems to suggest the contrary. Changes in the volatility and the persistence of the European real indicator and the national indicators in the post ECB and post-Euro samples are difficult to detect, but when they are present they are shared by Euro and non-Euro area countries.

One may argue that the decision to give up monetary policy and join the Euro was not entirely political and that countries endogenously selected into Euro and non-Euro members based on the similarities of their cyclical fluctuations. Since cyclical fluctuations and their changes in the two areas are quite alike, this possibility is quite remote.

We can think of at least three reasons for why our conclusions differ from those of Artis and Zhang. First, the 1970s were fundamentally different from the 1990s and 2000s, at least in terms of inflation movements and real- monetary interactions. Second, Artis and Zhang did not allow for time variations nor for cross country heterogeneous feedbacks in their analysis. Third, they focus on GDP data, while our indicators are constructed using a much broader set of macroeconomic data. To understand which of the difference could explain the opposite conclusions, we have in turn, estimated the model up to 1991; eliminated cross country feedbacks and time variations; used only GDP data in the model. It turns out that lack of time variations is the ingredient that makes results different: if we omit them from the model, we roughly recover Artis and Zhang's conclusion.

Figure 4 is more consistent with the view that the Maastricht treaty was important. In fact, all the statistics we present are different in the pre and post-Maastricht samples; the contemporaneous correlation of the national and the European indicator increases substantially in all cases, and the maximum correlation moves from lagged to contemporaneous. But is the Maastricht treaty responsible for these changes? Closer inspection shows that most of the changes predate the implementation of the Treaty and start taking 
place in the mid-1980. European and the national indicators are, in fact, highly correlated and cyclical fluctuations have become more synchronized in all countries at that time. The time gap is not necessarily inconsistent with the Maastricht treaty mattering: long anticipatory effects may be present when events are known in advance (see Bruckner and Pappa, 2011). However, the uncertainty surrounding the process that led to the signing of the Treaty, makes it difficult to believe that such anticipatory effects could credibly appear up to eight years before the Treaty was finally implemented.

In sum, European cyclical fluctuations change over time and the changes go in the direction of making national cycles more similar and more synchronous with the European cycle. The changes start taking place in the middle of the 1980s and the process appears to terminate in the middle of the 1990s. Thus, both the timing and the nature of the changes provide, prima facie, evidence against the idea that the creation of the ECB and the Euro changeover generated major variations in European business cycles. For the Maastricht treaty, conclusions are less clear cut but, even in this case, the association between changes in business cycle statistic and institutional changes is weak.

\subsection{Out-of-sample predictions}

To acquire more evidence on the effects that institutional changes had on cyclical fluctuations, we now turn to an out-of-sample unconditional forecasting exercise. The idea is simple: we want to see how bad our model is in forecasting the endogenous variables at the times when the events took place. If we can reasonably predict the time path of real series and if this is true for various forecasting horizons, then the institutional events of interest do not produce variations in the structure of business fluctuations in addition to those already built-in into the structure of the model.

We forecast the six endogenous variables of each country using the information available prior to the Maastricht treaty, the creation of the ECB and the Euro changeover. In particular, given the information available at 1993Q3, 1998Q3 and 2002Q1, we compute out-of-sample predictive distributions up to 6 quarters ahead. We then check whether the actual path of the variables falls within the 90 percent predictive tunnel. If it does 
not, institutional changes matter, at least in a forecasting sense. To save space, and given that results do not depend on the chosen variable, we report in figure 5 the predictive distributions for GDP growth only.

The forecasting outcomes depend on the event. While for most countries no forecast is outside the credible tunnel for more than a quarter, after the Euro changeover, the actual GDP growth path is outside the credible tunnel repeatedly over the forecasting horizon after the creation of the ECB for UK, Sweden, France, Belgium, Spain, the Netherlands. Since the model consistently underestimate GDP growth of these six countries while it is better for Germany, Italy, Denmark and Finland, national idiosyncrasies, rather than the creation of the ECB, could be responsible for the deviations we observe.

The forecasts performed around the date of the implementation of the Maastricht treaty are less accurate and for most countries actual GDP growth is outside of the 90 percent tunnel more than once over the forecasting horizon. There is however a pattern in the deviations in France, Germany, and to a lesser extent Belgium: forecasts tend to be more optimistic than the realized values over the first 2 quarters and more pessimistic over the last two quarters, perhaps as a result of the uncertainty concerning the consequences of the implementation of the Maastricht treaty. If forecasts were performed in 1992Q1 (the date when the Treaty was signed) the results are slightly better indicating that the uncertainty present in 1993Q4 was indeed an important factor.

As mentioned, the fact that we have three countries outside the Euro area, allows to compare the forecasts against an important benchmark. If the quality of the forecasts differs in the two groups of countries after the creation of the ECB and the Euro changeover, we can provide stronger evidence that these two institutional events had effects on the characteristics of real business cycles in Europe. Figure 5 indicates that this is not the case. Since this conclusion is insensitive to the dates we choose to forecast - for example, if we anticipate the forecasting dates by up to 4 quarters, the performance of the model is hardly affected - the creation of the ECB and the introduction of the Euro did not have any additional effect on European real business over and above those that time variations in the model would have predicted. 
It is possible that our forecasting exercises are not very powerful, especially if institutional changes have slow and delayed effects. While this is a valid argument for forecasts computed at short horizons, an earlier version of the paper showed that the conclusions are broadly maintained if forecasts are extended up to 5 years ahead. Thus, it is unlikely that lack of power is the reason for why our forecasting tests fail to recognize the creation of the ECB and the Euro changeover as major factors for European business cycles.

\subsection{The transmission of shocks}

Unconditional forecasting exercises are a useful benchmark but by their very same nature, they are not particularly informative about variations in the transmission of certain types of shocks. An unchanged unconditional forecasting performance could in fact be consistent with institutional changes mattering as long as the changes in the dynamic responses approximately average out across shocks.

To gather additional information, we therefore examine the transmission of two particular shocks. We consider both a "local" disturbance - a temporary German GDP growth shock - and an "external" shock - a temporary increase in the growth rate of US GDP. These two shocks are interesting because they provide information about nature of the intraeuropean and transatlantic transmission of disturbances, the magnitude of the synchronization and the significance of the heterogeneities present in the cyclical component of European countries. Once again, given the large number of variables in the system, we need to select which responses to report. Following the literature, we presents the responses of GDP growth to a German GDP growth shock (figure 6) and to a US GDP growth shock (figure 7) at 1993Q3, 1998Q3 and 2002Q1. We also present responses at 2007Q3, the commonly accepted starting point of the global financial crisis.

There are some changes in the transmission of a German growth shock over time, but they primarily involve the magnitude of the responses rather than the sign or the shape. A one standard error shock in the growth rate of German GDP has important spillovers on the GDP growth of other countries prior to Maastricht and, in half of the countries, the contemporaneous responses is up to 50 percent larger than in Germany. Spillovers 
remain important in the period between Maastricht and the creation of the ECB, but now the largest contemporaneous responses (occurring in the UK and Belgium) are only 35-40 larger than those in Germany. Spillovers uniformly increase after the creation of the ECB - now all nine countries responses are larger than the German GDP response - and excluding Finland, they remain roughly similar until the end of the sample. Interestingly, the idea that Germany has been the "locomotive" for growth in Europe has not been much affected by the three institutional changes of interest but its role has strengthened in the last decade. Note that spillovers are equally strong in Euro and non-Euro area countries and their relative importance has not changed much over time. Finally, since the largest spillovers have been always contemporaneous and the decay back to the steady state is similar, the timing of transmission of German growth shocks and the duration of the effects has not changed much over the last 20 years.

There has been considerable variation in the transmission of US growth shocks on European GDP growth. Before Maastricht transmission was weak and somewhat delayed; the magnitude and the persistence of responses increased in magnitude after Maastricht, and the peak response of GDP growth in Europe seem to lag by about two years the initial impulse. Responses become much smaller in the period between the creation of the ECB and the Euro changeover. Finally, at the end of the sample, the responses become again larger and heterogeneities more evident. Overall, a positive US GDP growth is expansionary in Europe; and the magnitude of the effect is not large, but quite persistent. Once again, neither the sign nor the shape of the responses have changed much over the last 20 years and the pattern is shared by both Euro area and non-Euro area countries. Thus, the Maastricht treaty, the creation of the ECB and the Euro changeover have not affected much the features of the transatlantic transmission of real shocks: there has been an intensification of the links, but not much else.

\section{Conclusions}

This paper examines the effect that institutional changes have on the dynamics of business cycles by focusing on the recent European experience and three events occurred in the last 
20 years: the Maastricht treaty, the creation of the ECB and the Euro changeover. To the best of our knowledge, we are the first to investigate the relationship between institutional changes and business cycles. The recent sovereign debt crises has triggered expectations of further changes in European institutions and our analysis can help to predict how European business cycles will shape after the expected changes in Governance.

To study the questions of interest a panel VAR model is estimated using quarterly data for six variables in ten European countries, seven which adopted the Euro and three which did not - the latter is used as control group. We document the time evolution of European and national cyclical fluctuations; report reduced form statistics characterizing their features over time; conduct an out-of-sample forecasting exercise and trace out the dynamics of the endogenous variables in response to shocks at different dates.

The features of European and national cycles have changed over time: we detect important variations in the volatility, and a higher conformity between national and European fluctuations as time goes by. These variations, however, predate the events of interest, are shared by both Euro area and non-Euro area countries, and appear to be linked to a general process of convergence and synchronization taking place in Europe in the 1980-90s. Our model can predict well output growth fluctuations after the creation of the ECB and the Euro changeover. We discover changes in the intensity of the transmission of certain disturbances, but the propagation profile is largely unaffected to the events of interest.

Thus, while the creation of the ECB and the Euro changeover are not major events for European real business cycles, one may have some doubts about the consequences of the Maastricht Treaty. We have argued that it is difficult to appeal to the potential predictability of the event to account for the changes which began to take place in the mid-1980s, especially taking into account that there was considerable uncertainty about the feasibility of the treaty. Nevertheless, one has to admit that little is known about the empirical consequences of predictable institutional changes.

The evidence we present has important implications for the literature concerned with common currency areas, the effects of large monetary events, the effects of national idiosyncrasies and the relationship between business and medium term cycles. The process 
of real convergence we discover predates the three institutional changes we consider; large monetary events had minor effects on both the nature and the structure of real fluctuations; national idiosyncrasies matter less but they are not fading away; and business cycles are more similar across countries but not necessarily more related to those medium term fluctuations, which is now fashionable to study (see Gertler and Comin, 2006). Both academic and policymakers should pay attention to these results since they depart somewhat from what the conventional wisdom likes to stress. 


\section{References}

[1] Alesina, A., 1988. Macroeconomics and Politics. NBER Macroeconomic Annual, 3, $13-52$.

[2] Artis, M., Zhang, W. ,1997. International Business Cycles and the ERM: is there a European Business Cycle?. International Journal of Finance and Economics, 2, 1-16.

[3] Ball, L., 2010. The Performance of Alternative Monetary Regimes, in: Friedman, B.M., Woodford, M. (Eds.), Handbook of Monetary Economics, Vol.3. North-Holland, Amsterdam, 1303-1343.

[4] Bayoumi, T., Helbling, T., 2003. Are They All in the Same Boat? The 2000-2001 Growth Slowdown and the G-7 Business Cycle Linkages. IMF Working Paper 03/46.

[5] Bergman, U., Bordo, M., Jonung, L. 1998. Historical Evidence on Business Cycles: the International Experience, Conference Series Proceedings, Federal Reserve Bank of Boston, 65-119.

[6] Bruckner, M., Pappa, E., 2011. For an Olive Wreath? Olympic Games and Anticipation Effects in Macroeconomics, UAB manuscript.

[7] Canova, F., 2007. Methods for Applied Macroeconomic Research, Princeton University Press, Princeton, NJ.

[8] Canova, F., Ciccarelli, M., 2009. Estimating Multi-country VAR models. International Economic Review 50, 929-961.

[9] Canova, F., Ciccarelli, M., Ortega, E., 2007. Similarities and Convergence in G-7 Cycles. Journal of Monetary Economics 54, 850-878.

[10] Canova, F., Gambetti, L., 2009. Structural Changes in the US economy, Is there a role for Monetary Policy. Journal of Economic Dynamics and Control 33, 477-490.

[11] Chib, S., Greenberg, E., 1995. Hierarchical Analysis of SUR Models with Extensions to Correlated Serial Errors and Time-Varying Parameter Models. Journal of Econometrics 68, 409-431.

[12] Cogley, T., Sargent, T., 2005. Drifts and Volatilities: Monetary Policy and Outcomes in the post WWII US. Review of Economic Dynamics 8, 262-302. 
[13] Del Negro, M., Otrok, C., 2008. Dynamic Factor Models with Time-Varying Parameters: Measuring Changes in International Business Cycles, Federal Reserve Bank of New York Staff Reports 326.

[14] Doan, T., Litterman R., Sims, C., 1984. Forecasting and Conditional Projections Using Realist Prior Distributions. Econometric Reviews 3(1), 1-100.

[15] Forni, M., Reichlin, L., 1998. Let's Get Real: A Factor Analytic Approach to Disaggregated Business Cycle Dynamics. Review of Economic Studies 65, 453-473.

[16] Gertler, M., Comin, D., 2006. Medium-Term Business Cycles. American Economic Review 96(3), 523-551.

[17] Geweke, J., 2000. Simulation Based Bayesian Inference for Economic Time Series, in: Mariano, R., Schuermann, T., Weeks, M. (Eds.), Simulation Based Inference in Econometrics: Methods and Applications, Cambridge University Press, Cambridge, UK, pp.255-299.

[18] Giannone, D., Reichlin, L., 2006. Trends and Cycles in the Euro Area: How Much Heterogeneity and Should We Worry About?. ECB Working Paper no. 595.

[19] Kadiyala, K.R., Karlsson, S., 1997. Numerical Methods for Estimation and Inference in Bayesian-VAR Models. Journal of Applied Econometrics 12, 99-132.

[20] Lubik, T., Schorfheide, F., 2004. Testing for Indeterminacy: An Application to the US. American Economic Review 94, 190-217.

[21] Primiceri, G. 2005. Time Varying Structural Vector Autoregressions and Monetary Policy. The Review of Economic Studies 72, 821-852.

[22] Sargent, T., 1989. Two Models of Measurement and the Investment Accelerator. Journal of Political Economy 97, 251-287.

[23] Stock, J., Watson, M., 1989. New Indexes of Coincident and Leading Economic Indicators, in: Blanchard, O., Fisher, S. (Eds.), NBER Macroeconomics Annual, Vol. 4. M.I.T. Press.

[24] Stock, J. Watson, M., 2003. Understanding Changes in International Business Cycle Dynamics. Journal of the European Economic Association 3, 968-1006. 
Figure 1. Common real European indicators and GDP growth

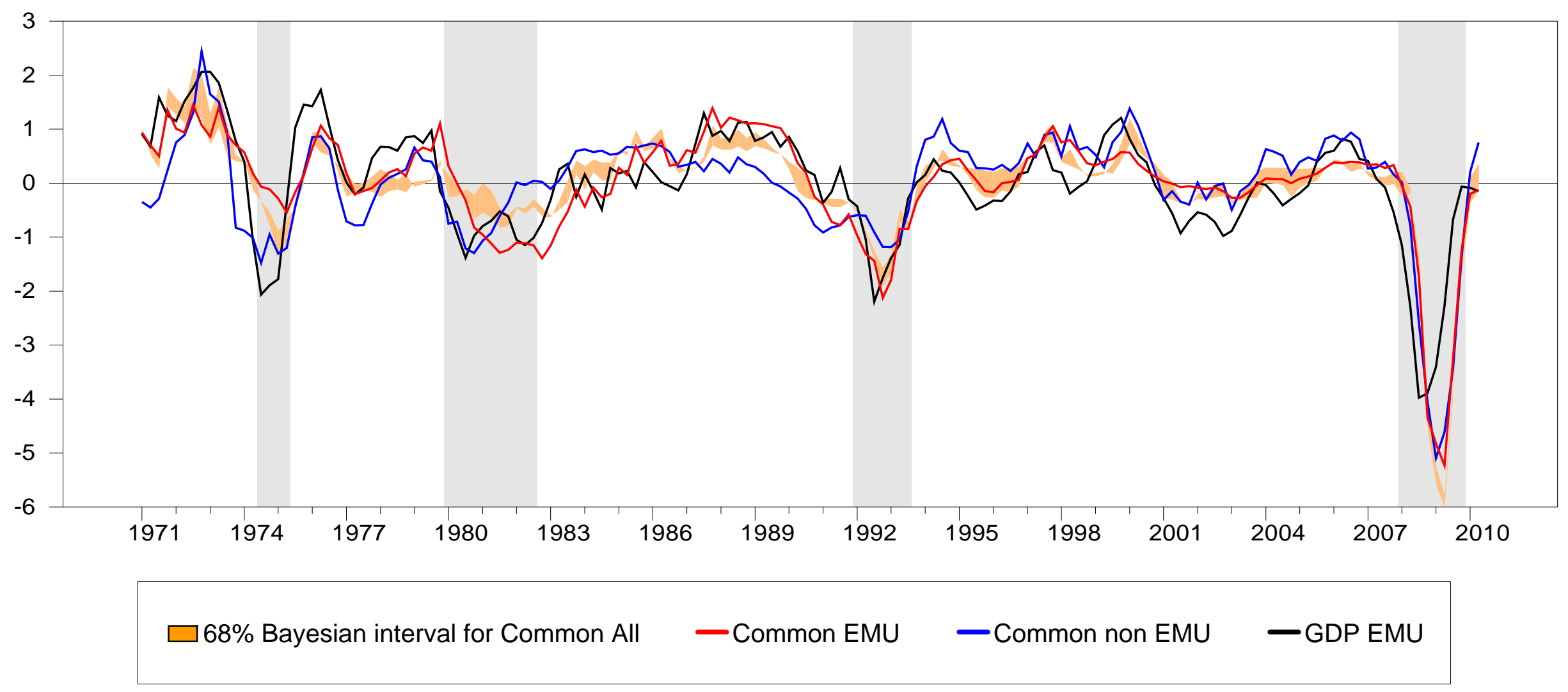


Standard deviations of GDP growth

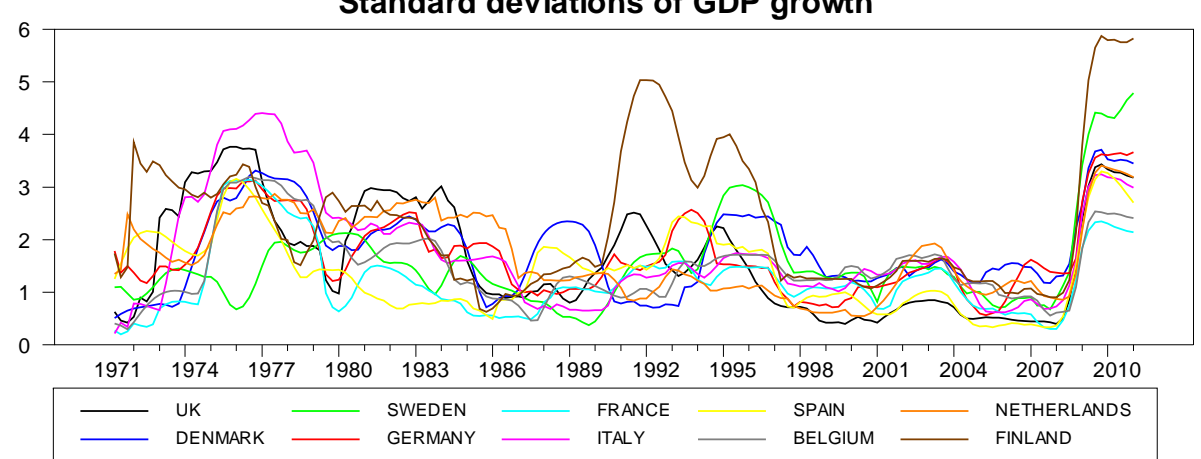

AR(1) coefficients of GDP growth

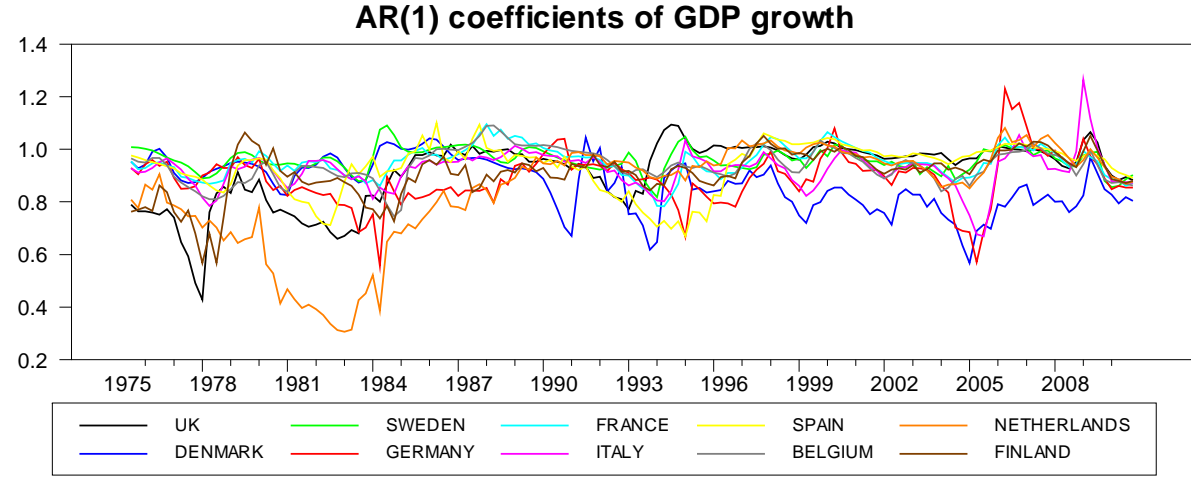

Maximum correlations between GDP and investment growth

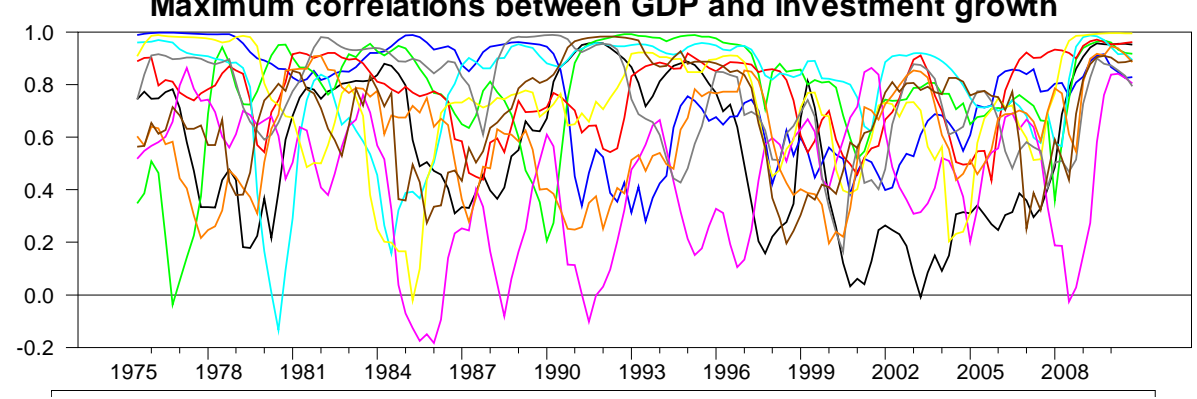

Standard deviations of Investment growth

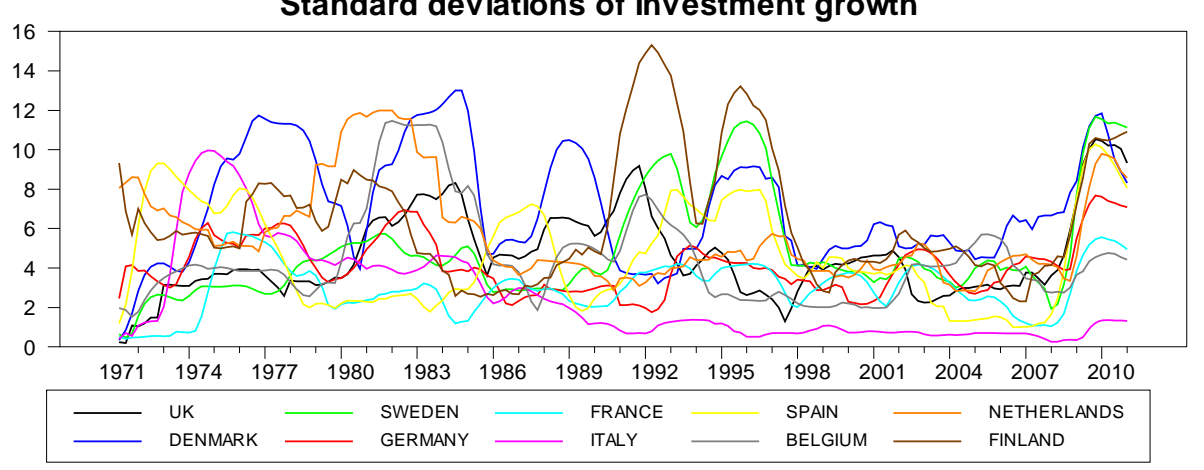

AR(1) coefficients of Investment growth

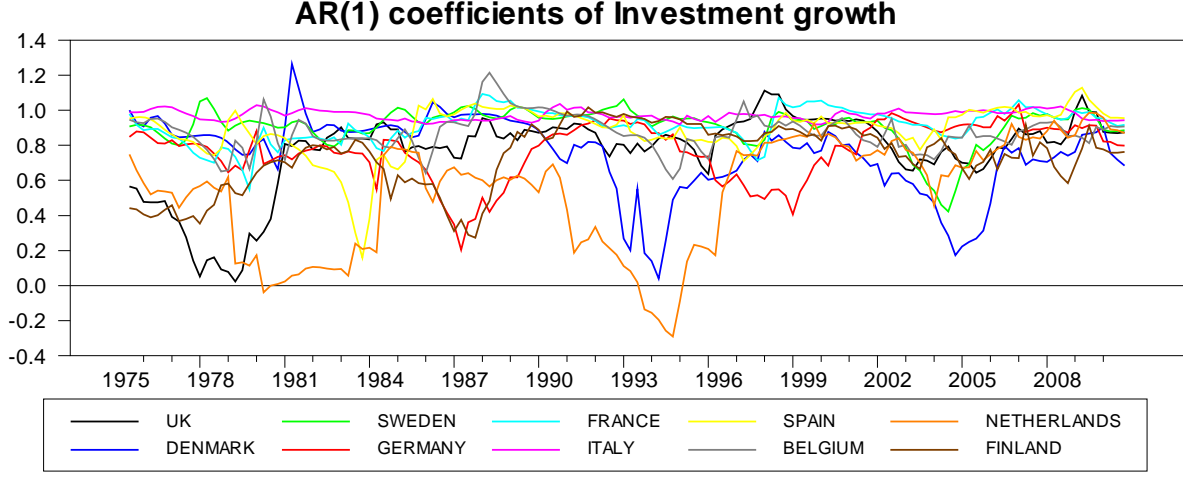

Contemporaneous Correlations between GDP and investment growth

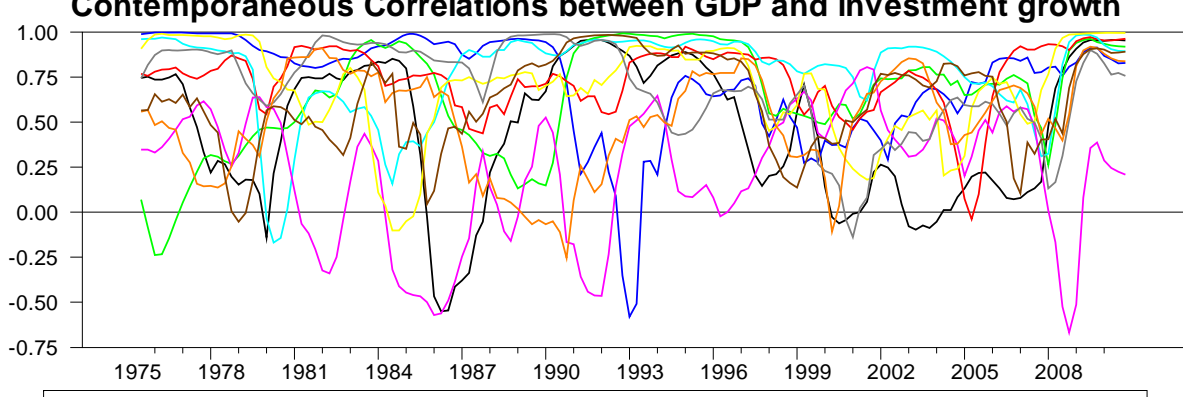




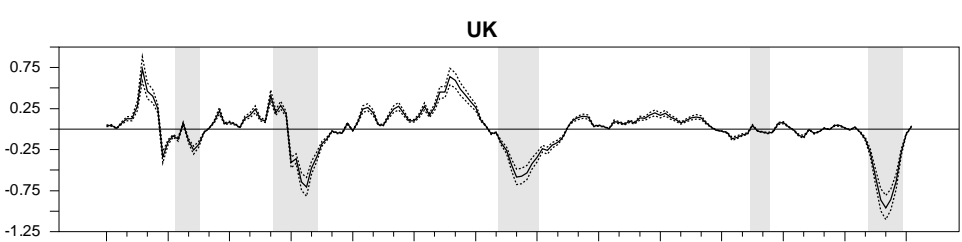

$\begin{array}{lllllllllllllllll}1971 & 1974 & 1977 & 1980 & 1983 & 1986 & 1989 & 1992 & 1995 & 1998 & 2001 & 2004 & 2007 & 2010\end{array}$ DENMARK

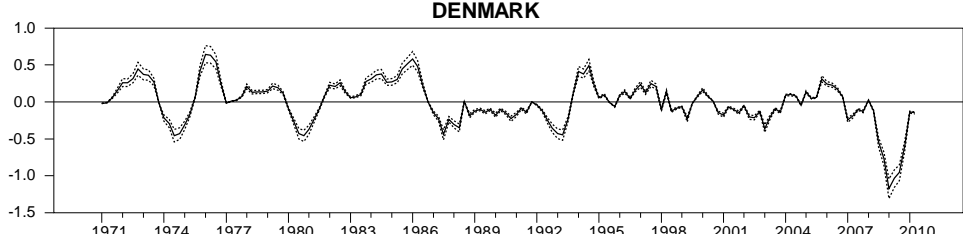

$\begin{array}{lllllllllllllll}1971 & 1974 & 1977 & 1980 & 1983 & 1986 & 1989 & 1992 & 1995 & 1998 & 2001 & 2004 & 2007 & 2010\end{array}$ SWEDEN

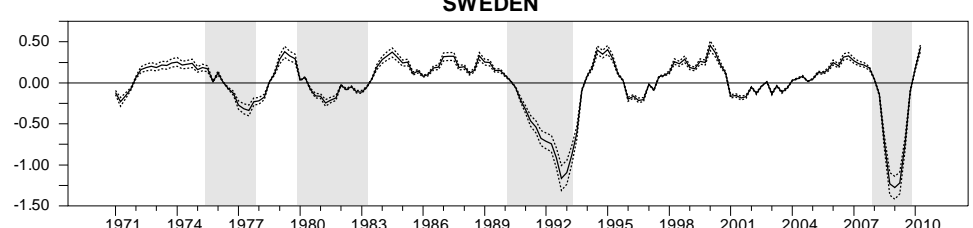

GERMANY

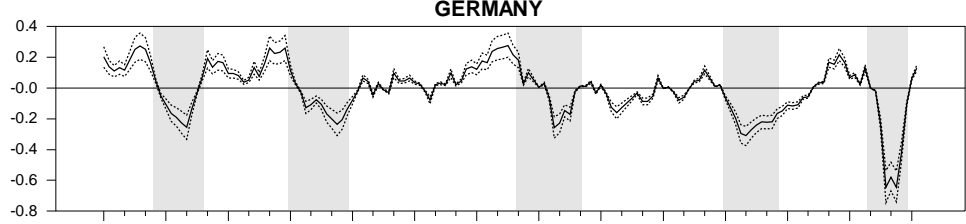

$\begin{array}{llllllllllllllll}1971 & 1974 & 1977 & 1980 & 1983 & 1986 & 1989 & 1992 & 1995 & 1998 & 2001 & 2004 & 2007 & 2010\end{array}$

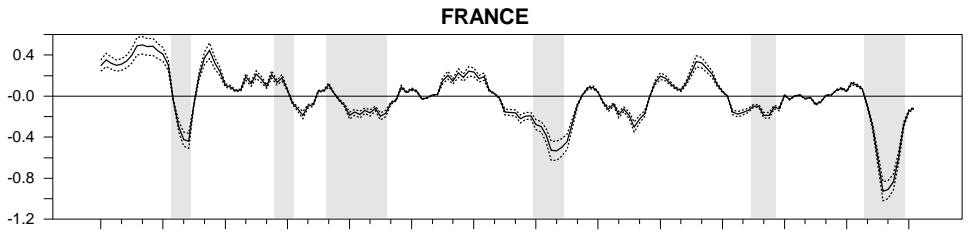

$\begin{array}{lllllllllllllll}1971 & 1974 & 1977 & 1980 & 1983 & 1986 & 1989 & 1992 & 1995 & 1998 & 2001 & 2004 & 2007 & 2010\end{array}$

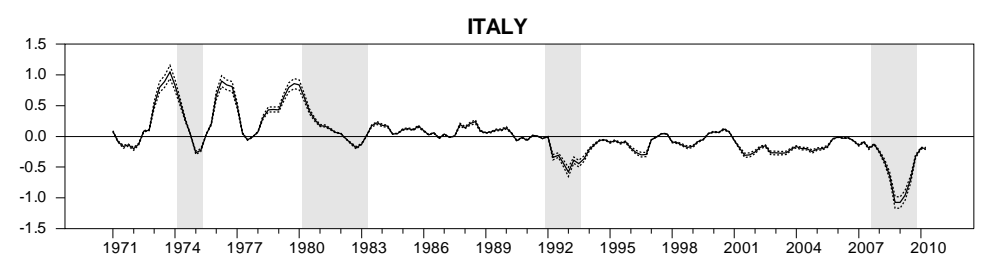

SPAIN

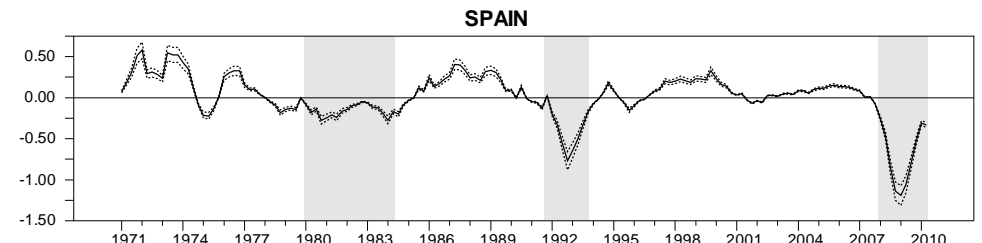

BELGIUM

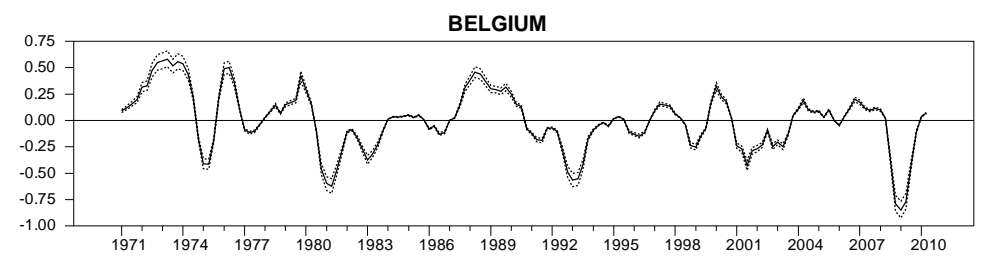

NETHERLANDS

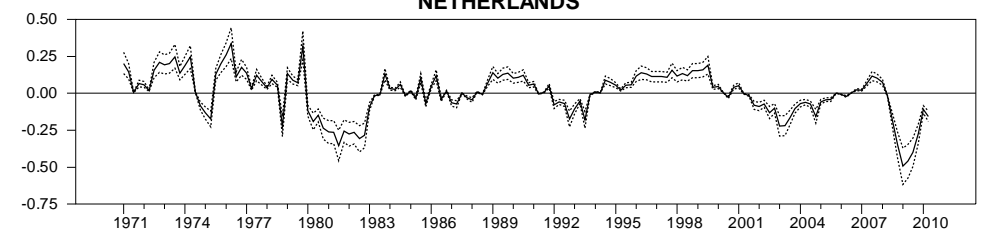

FINLAND

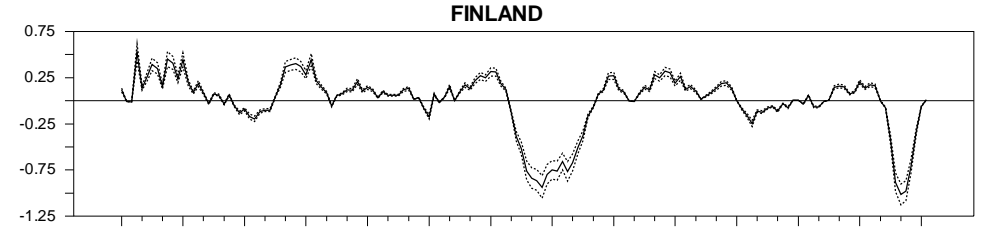

$\begin{array}{lllllllllllllll}1 & 1971 & 1974 & 1977 & 1980 & 1983 & 1986 & 1989 & 1992 & 1995 & 1998 & 2001 & 2004 & 2007 & 2010\end{array}$ 
Standard deviations
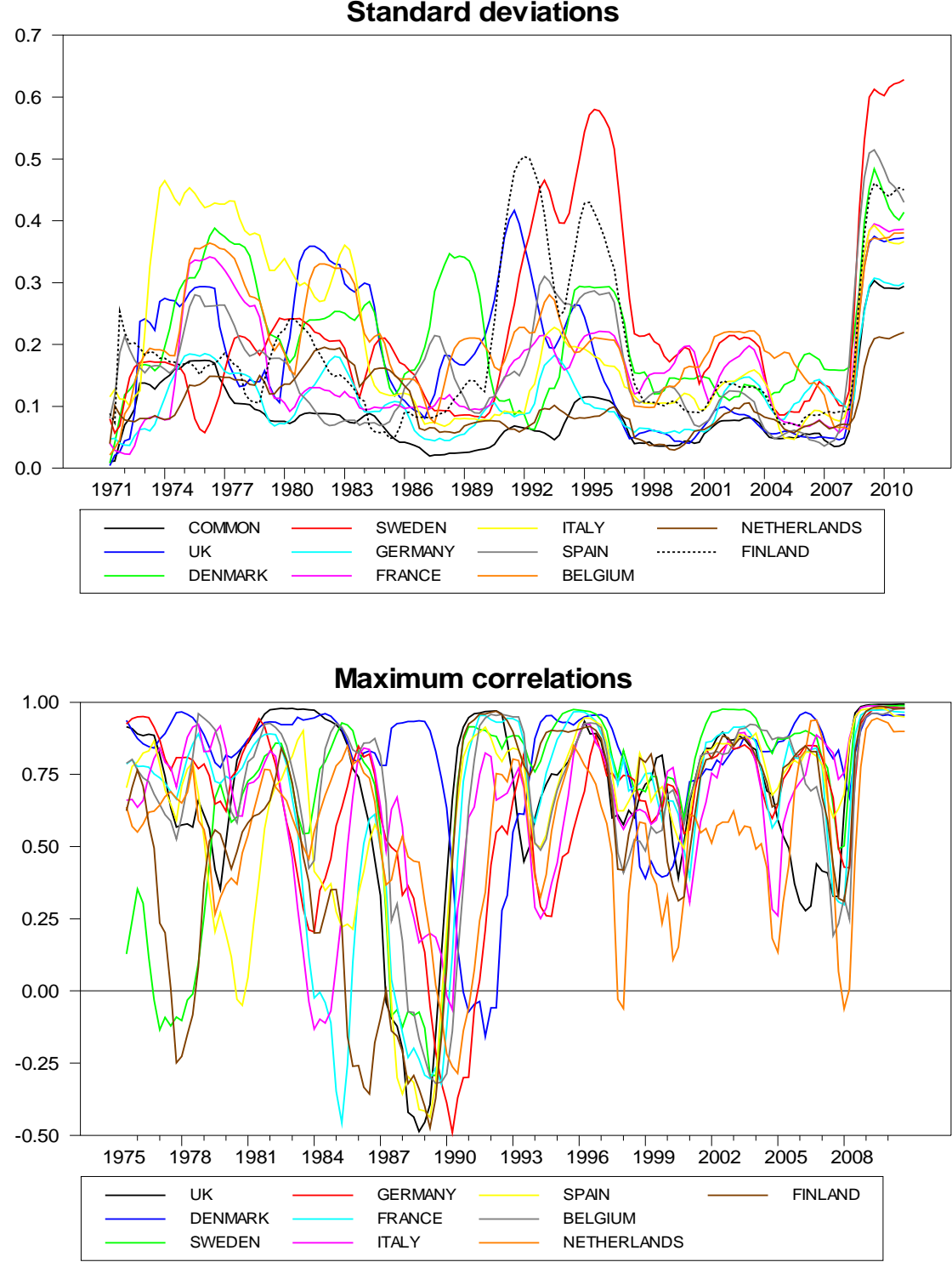

AR(1) coefficients
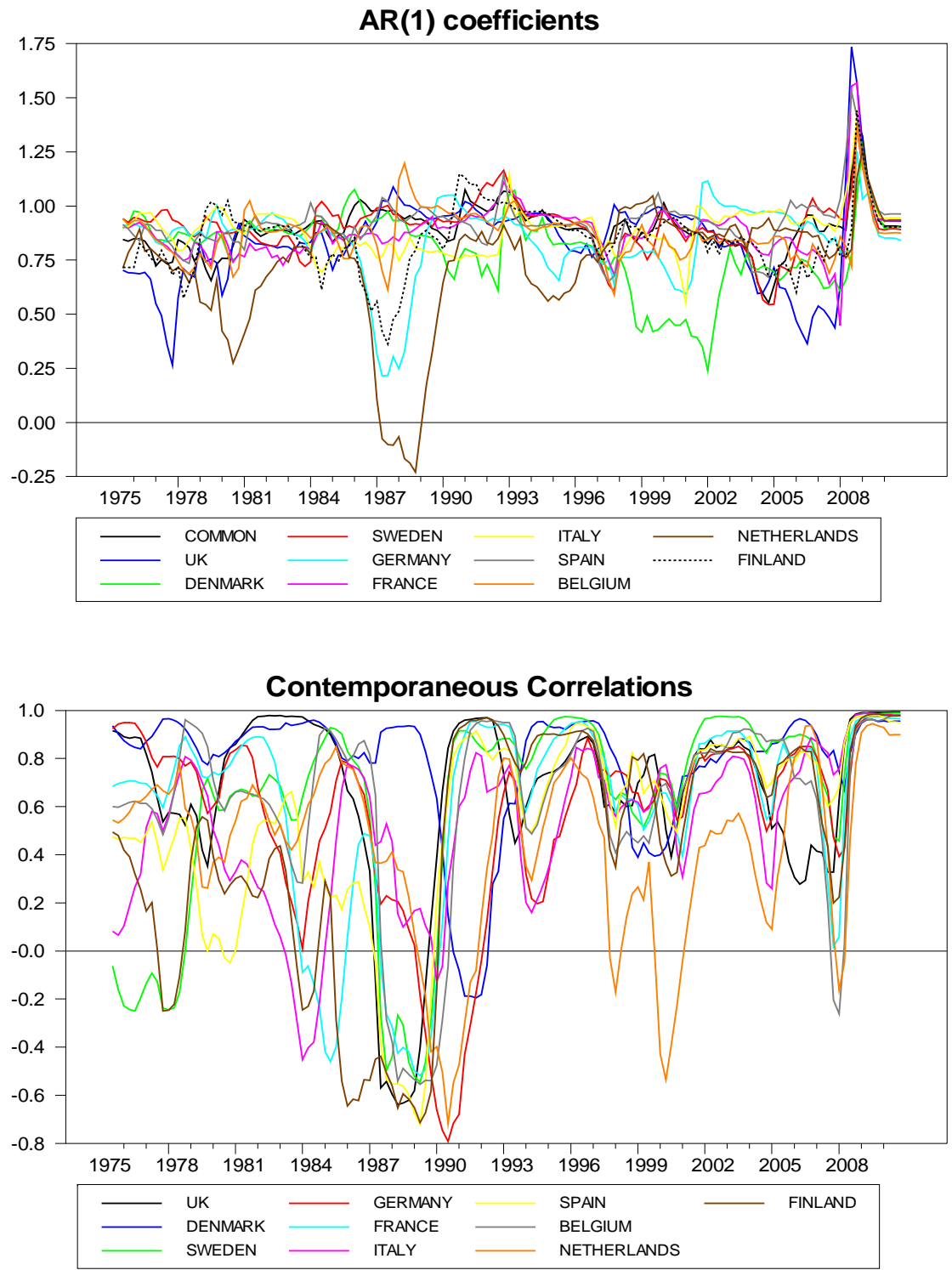


\section{Figure 5: Out-of-Sample forecast of GDP growth}
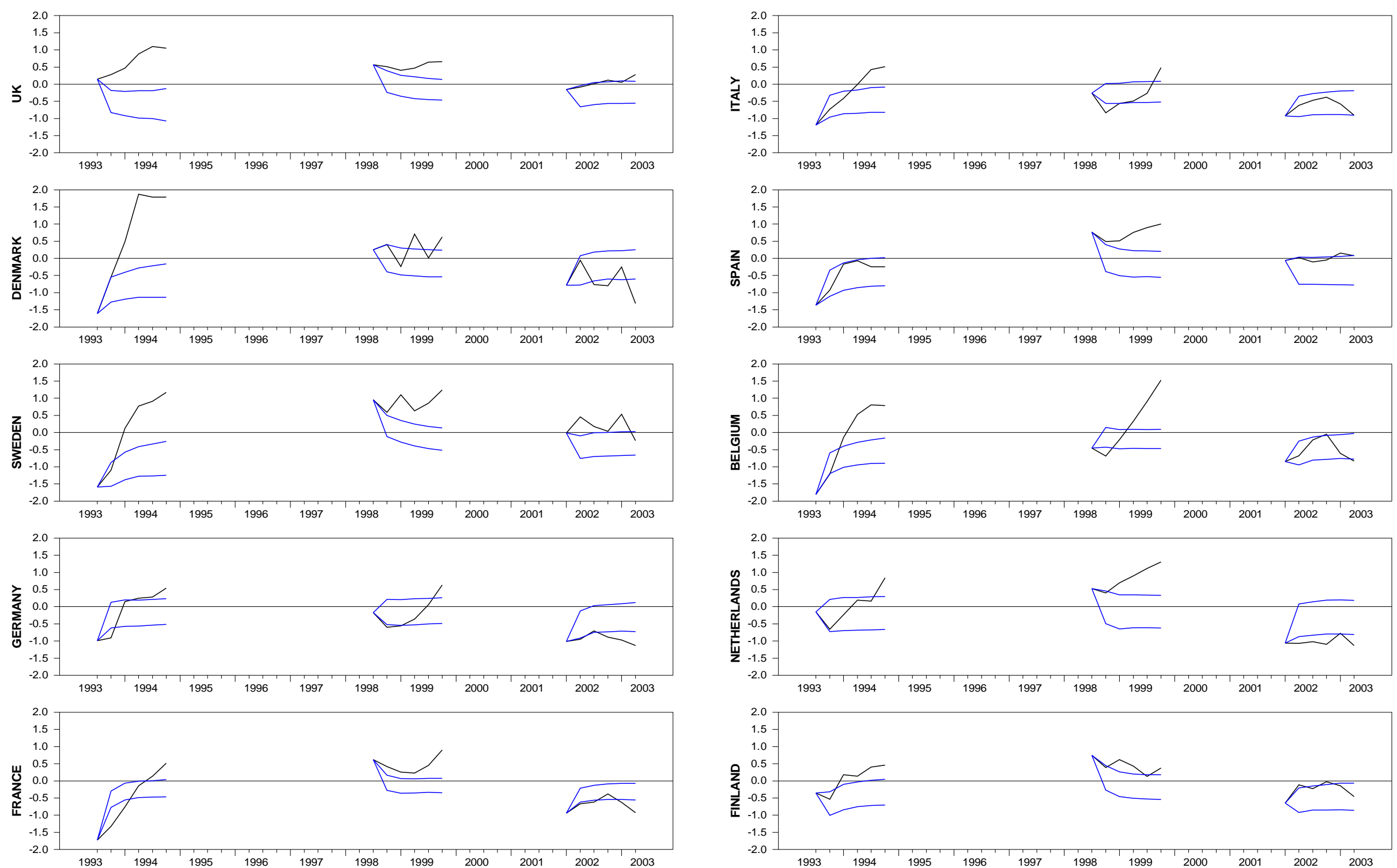
Figure 6. Responses of GDP growth to one standard error increase in German real activity

UK
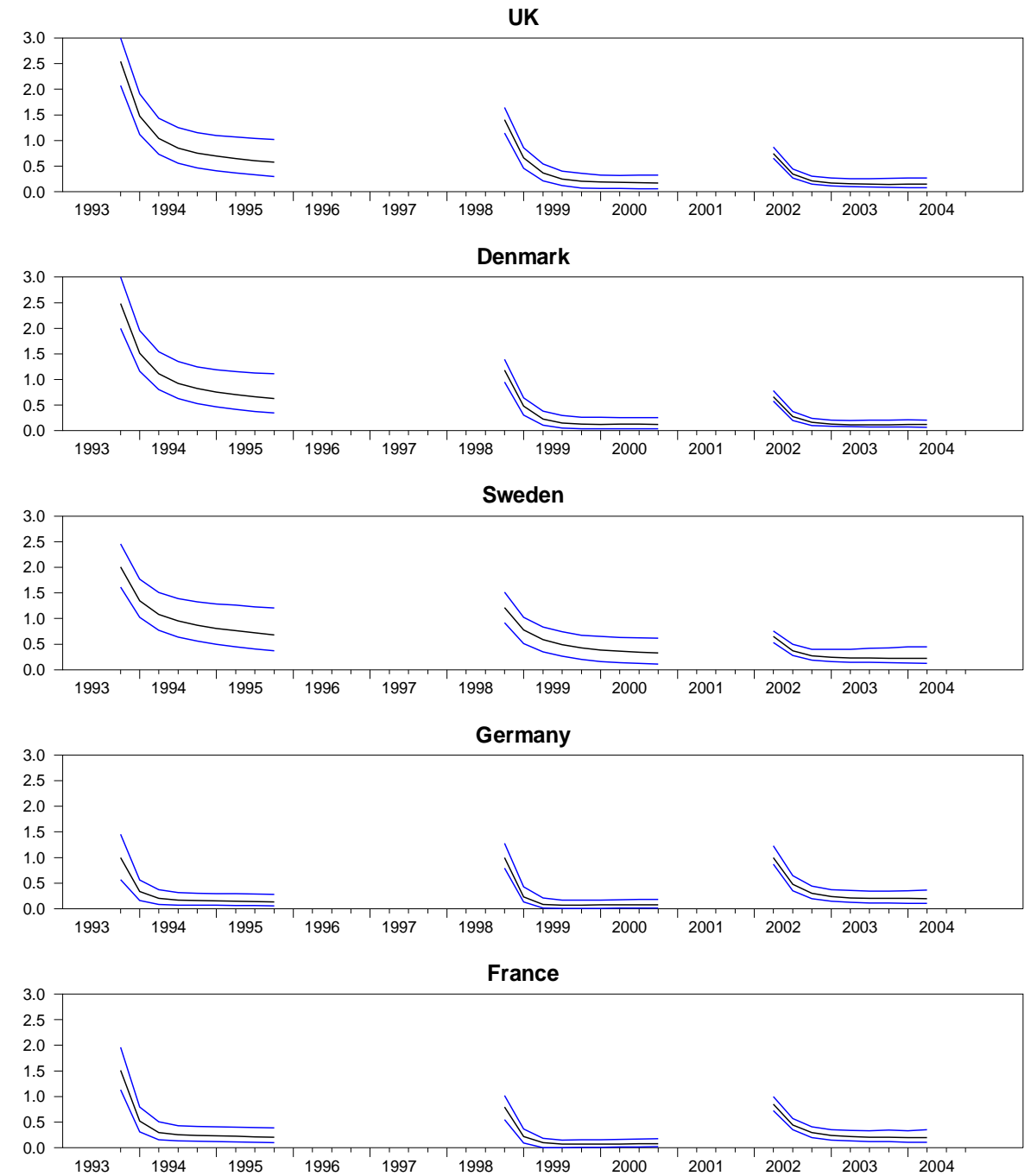

Italy

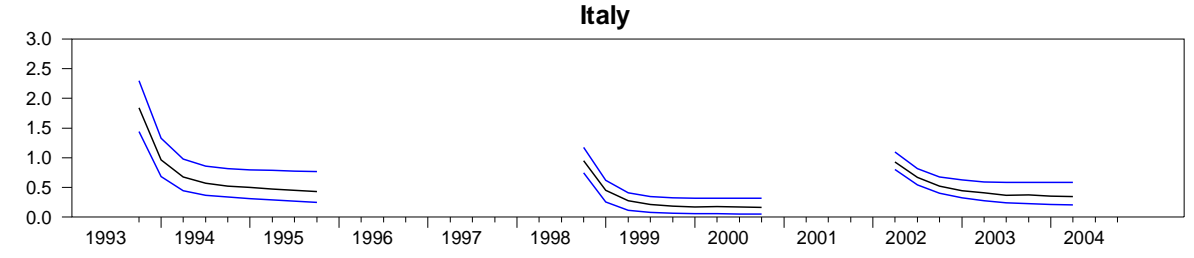

Spain

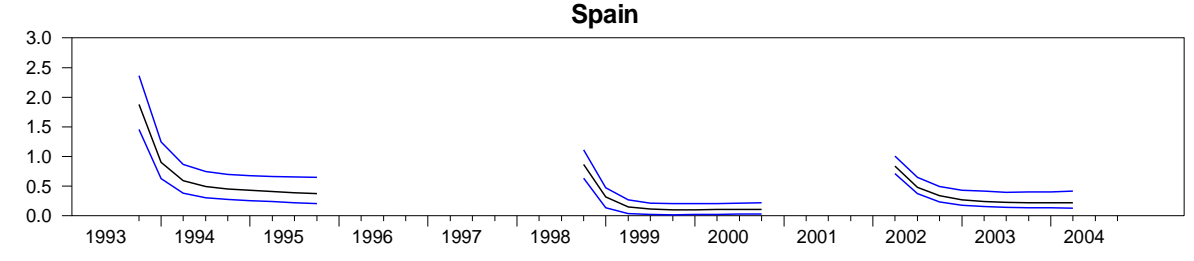

Belgium

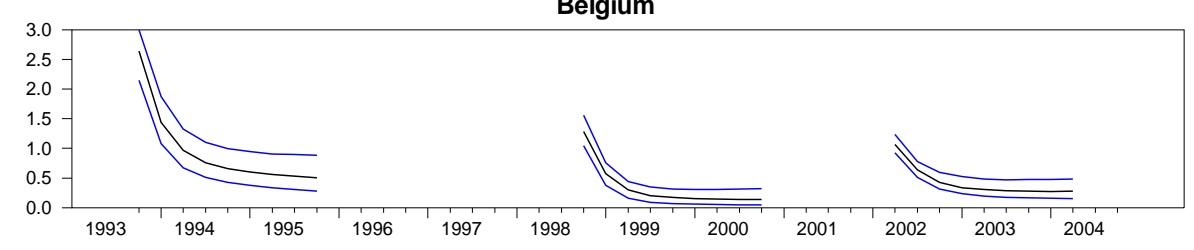

Netherlands

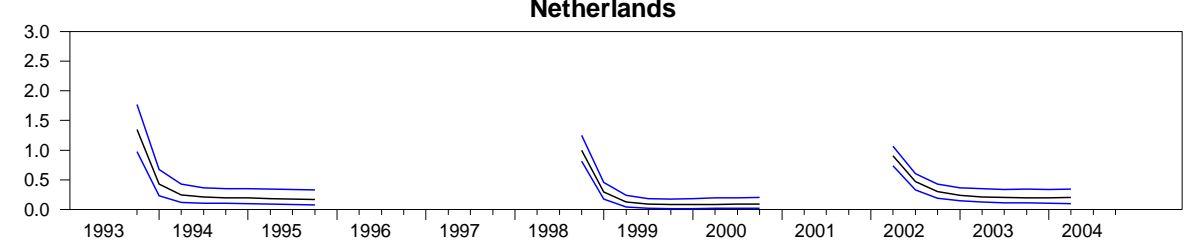

Finland

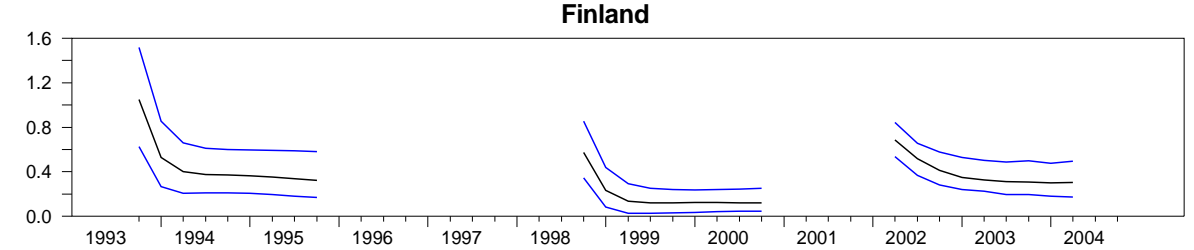


Figure 7. Responses of GDP growth to one standard error increase in US GDP growth
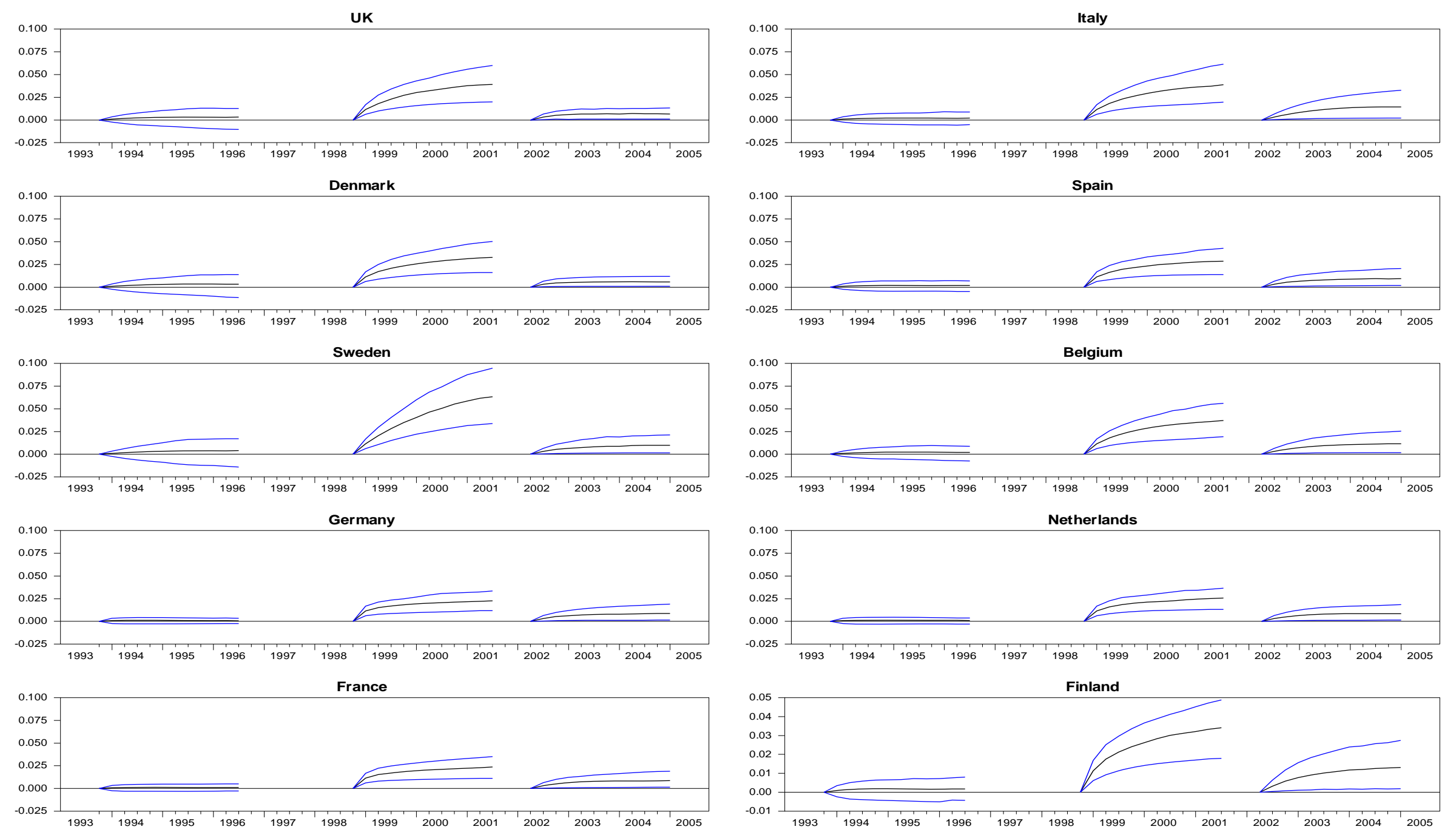
Table A1. Reduced form statistics of real indicators

\begin{tabular}{|c|c|c|c|c|c|c|c|c|c|c|c|c|}
\hline & COMMON & UK & DK & SW & $\mathrm{DE}$ & $\mathrm{FR}$ & IT & $\mathrm{SP}$ & $\mathrm{BE}$ & $\mathrm{NL}$ & $\mathrm{FI}$ & EMU GDP \\
\hline \multicolumn{13}{|c|}{ Full sample: 1971Q1-2010Q4 } \\
\hline $\begin{array}{l}\text { S.D. } \\
\text { AR(1) } \\
\text { Corr (lag) } \\
\text { corr at 0 }\end{array}$ & $\begin{array}{l}0.14 \\
0.89\end{array}$ & $\begin{array}{c}0.27 \\
0.88 \\
0.80(0)\end{array}$ & $\begin{array}{c}0.29 \\
0.87 \\
0.80(0)\end{array}$ & $\begin{array}{c}0.34 \\
0.92 \\
0.74(0)\end{array}$ & $\begin{array}{c}0.17 \\
0.88 \\
0.64(0)\end{array}$ & $\begin{array}{c}0.25 \\
0.92 \\
0.69(0)\end{array}$ & $\begin{array}{c}0.34 \\
0.92 \\
0.47(-1) \\
0.41 \\
\end{array}$ & $\begin{array}{c}0.29 \\
0.94 \\
0.72(0)\end{array}$ & $\begin{array}{c}0.28 \\
0.89 \\
0.62(0)\end{array}$ & $\begin{array}{c}0.15 \\
0.80 \\
0.62(-1) \\
0.59 \\
\end{array}$ & $\begin{array}{c}0.31 \\
0.91 \\
0.65(0)\end{array}$ & $\begin{array}{c}1.88 \\
0.95 \\
0.77(0)\end{array}$ \\
\hline \multicolumn{13}{|c|}{ Pre Maastricht: 1971Q1-1993Q3 } \\
\hline $\begin{array}{l}\text { S.D. } \\
\text { AR(1) } \\
\text { Max corr } \\
\text { corr at } 0\end{array}$ & $\begin{array}{l}0.10 \\
0.88\end{array}$ & $\begin{array}{c}0.29 \\
0.86 \\
0.77(0)\end{array}$ & $\begin{array}{c}0.28 \\
0.89 \\
0.75(0)\end{array}$ & $\begin{array}{c}0.33 \\
0.97 \\
0.55(-1) \\
0.54 \\
\end{array}$ & $\begin{array}{c}0.14 \\
0.90 \\
0.51(0) \\
0.51 \\
\end{array}$ & $\begin{array}{c}0.25 \\
0.93 \\
0.61(-1) \\
0.58 \\
\end{array}$ & $\begin{array}{c}0.34 \\
0.92 \\
0.52(-2) \\
0.25 \\
\end{array}$ & $\begin{array}{c}0.27 \\
0.92 \\
0.57(-2) \\
0.48 \\
\end{array}$ & $\begin{array}{c}0.30 \\
0.92 \\
0.65(-1) \\
0.57 \\
\end{array}$ & $\begin{array}{c}0.15 \\
0.72 \\
0.46(-1) \\
0.41 \\
\end{array}$ & $\begin{array}{l}0.34 \\
0.93 \\
0.45\end{array}$ & $\begin{array}{l}1.82 \\
0.95 \\
0.71\end{array}$ \\
\hline \multicolumn{13}{|c|}{ Post Maastricht: 1993Q4-2010Q3 } \\
\hline $\begin{array}{l}\text { S.D. } \\
\text { AR(1) } \\
\text { Max corr } \\
\text { corr at } 0\end{array}$ & $\begin{array}{l}0.18 \\
0.90\end{array}$ & $\begin{array}{c}0.24 \\
0.93 \\
0.96(0)\end{array}$ & $\begin{array}{c}0.31 \\
0.84 \\
0.91(0)\end{array}$ & $\begin{array}{c}0.35 \\
0.85 \\
0.93(0)\end{array}$ & $\begin{array}{c}0.17 \\
0.87 \\
0.84(0)\end{array}$ & $\begin{array}{c}0.25 \\
0.90 \\
0.89(0)\end{array}$ & $\begin{array}{c}0.23 \\
0.92 \\
0.93(0)\end{array}$ & $\begin{array}{c}0.32 \\
0.95 \\
0.92(0)\end{array}$ & $\begin{array}{c}0.23 \\
0.83 \\
0.83(0)\end{array}$ & $\begin{array}{c}0.15 \\
0.90 \\
0.81(-1) \\
0.80 \\
\end{array}$ & $\begin{array}{c}0.27 \\
0.88 \\
0.94(0)\end{array}$ & $\begin{array}{c}1.88 \\
0.95 \\
0.94(1) \\
0.82 \\
\end{array}$ \\
\hline \multicolumn{13}{|c|}{ Post ECB creation: 1998Q3-2010Q4 } \\
\hline $\begin{array}{l}\text { S.D. } \\
\text { AR(1) } \\
\text { Max corr } \\
\text { corr at } 0\end{array}$ & $\begin{array}{l}0.20 \\
0.90\end{array}$ & $\begin{array}{c}0.26 \\
0.92 \\
0.97(0)\end{array}$ & $\begin{array}{c}0.31 \\
0.87 \\
0.94(0)\end{array}$ & $\begin{array}{c}0.40 \\
0.89 \\
0.97(0)\end{array}$ & $\begin{array}{c}0.20 \\
0.88 \\
0.85(0)\end{array}$ & $\begin{array}{c}0.28 \\
0.92 \\
0.94(0)\end{array}$ & $\begin{array}{c}0.26 \\
0.94 \\
0.95(0)\end{array}$ & $\begin{array}{c}0.37 \\
0.96 \\
0.94(0)\end{array}$ & $\begin{array}{c}0.26 \\
0.86 \\
0.85(0)\end{array}$ & $\begin{array}{c}0.15 \\
0.91 \\
0.81(-1) \\
0.80 \\
\end{array}$ & $\begin{array}{c}0.29 \\
0.89 \\
0.96(0)\end{array}$ & $\begin{array}{c}2.15 \\
0.94 \\
0.95(1) \\
0.83 \\
\end{array}$ \\
\hline \multicolumn{13}{|c|}{ Post Euro changeover: 2002Q1-2010Q4 } \\
\hline $\begin{array}{l}\text { S.D. } \\
\text { AR(1) } \\
\text { Max corr } \\
\text { corr at } 0\end{array}$ & $\begin{array}{l}0.22 \\
0.91\end{array}$ & $\begin{array}{c}0.28 \\
0.92 \\
0.98(0)\end{array}$ & $\begin{array}{c}0.36 \\
0.88 \\
0.94(0)\end{array}$ & $\begin{array}{c}0.44 \\
0.89 \\
0.97(0)\end{array}$ & $\begin{array}{c}0.22 \\
0.87 \\
0.85(0)\end{array}$ & $\begin{array}{c}0.28 \\
0.93 \\
0.96(0)\end{array}$ & $\begin{array}{c}0.28 \\
0.94 \\
0.97(0)\end{array}$ & $\begin{array}{c}0.40 \\
0.96 \\
0.94(0)\end{array}$ & $\begin{array}{c}0.28 \\
0.86 \\
0.91(0)\end{array}$ & $\begin{array}{c}0.15 \\
0.93 \\
0.86(-1) \\
0.85 \\
\end{array}$ & $\begin{array}{c}0.32 \\
0.89 \\
0.97(0)\end{array}$ & $\begin{array}{c}2.30 \\
0.92 \\
0.96(1) \\
0.82 \\
\end{array}$ \\
\hline
\end{tabular}

S.D. is the standard deviation; AR(1) the first autoregressive coefficient; Corr(lag) the largest correlation with the common cycle indicator and the lag at which it occurs (a negative lag means that the common indicator is leading); corr at 0 is the contemporaneous correlation when different from the previous. 
Table A2. Growth rate cycle turning points. Full sample: 1971Q1-2010Q4

\begin{tabular}{|c|c|c|c|c|c|c|c|c|c|c|c|c|}
\hline Period & Peak or Trough & COMMON & UK & DK & sw & $\mathrm{DE}$ & FR & IT & $\mathrm{SP}$ & $\mathrm{BE}$ & $\mathrm{NL}$ & $\mathrm{FI}$ \\
\hline 1969-1971 & $\begin{array}{l}P \\
T\end{array}$ & & 7103 & & & 7103 & & & & & 7103 & 7103 \\
\hline \multirow{2}{*}{ 1971-1972 } & $P$ & $72 \mathrm{Q} 4$ & $72 \mathrm{Q} 4$ & $72 \mathrm{Q} 4$ & & $72 \mathrm{Q} 4$ & & & 72Q1 & & & \\
\hline & $\mathrm{T}$ & & 73Q4 & & & & & 72Q1 & & & & \\
\hline \multirow{2}{*}{ 1973-1975 } & $P$ & & $74 \mathrm{Q} 4$ & & 74Q1 & & 73Q1 & $73 Q 4$ & & $73 Q_{2}$ & $73 \mathrm{Q} 3$ & $73 Q^{2}$ \\
\hline & $T$ & $74 \mathrm{Q} 3$ & $75 \mathrm{Q}^{2}$ & $74 \mathrm{Q} 3$ & & 75Q1 & $75 Q^{2}$ & 75Q1 & $75 Q^{2}$ & $75 \mathrm{Q} 2$ & $75 \mathrm{Q} 2$ & $75 \mathrm{Q} 2$ \\
\hline \multirow{2}{*}{$1975-1979$} & $P$ & $76 \mathrm{Q} 2$ & $76 Q^{3}$ & 76Q1 & & 76Q1 & 76Q2 & $76 \mathrm{Q} 2$ & $76 Q 3$ & $76 \mathrm{Q} 2$ & $76 \mathrm{Q} 2$ & $76 \mathrm{Q} 2$ \\
\hline & $\mathrm{T}$ & $77 \mathrm{Q} 2$ & $77 Q^{3}$ & 77Q1 & 77Q3 & $77 Q 4$ & $77 \mathrm{Q} 3$ & $77 \mathrm{Q3}$ & $78 Q 4$ & $77 \mathrm{Q} 2$ & $77 \mathrm{Q} 2$ & $77 Q^{3}$ \\
\hline \multirow{2}{*}{ 1979-1981 } & $P$ & 79Q1 & 79Q1 & 79Q2 & $79 Q 2$ & $79 \mathrm{Q} 4$ & $78 \mathrm{Q} 3$ & $79 Q 4$ & $79 Q 4$ & $79 \mathrm{Q} 4$ & $78 Q 2$ & \\
\hline & $\mathrm{T}$ & $80 \mathrm{Q} 4$ & $80 \mathrm{Q} 4$ & $80 \mathrm{Q} 4$ & $81 \mathrm{Q}^{2}$ & $80 \mathrm{Q} 4$ & $80 \mathrm{Q} 4$ & & $80 \mathrm{Q} 4$ & $81 \mathrm{Q} 2$ & $78 \mathrm{Q} 4$ & \\
\hline \multirow{2}{*}{ 1981-1983 } & $P$ & $82 \mathrm{Q} 3$ & & $82 \mathrm{Q} 3$ & $82 \mathrm{Q} 1$ & $81 \mathrm{Q} 2$ & 82Q1 & & $82 \mathrm{Q} 4$ & $82 \mathrm{Q} 2$ & $79 Q 4$ & $80 \mathrm{Q}^{2}$ \\
\hline & T & $83 \mathrm{Q} 1$ & & 83Q1 & 83Q1 & $82 \mathrm{Q} 2$ & $83 \mathrm{Q} 1$ & $82 \mathrm{Q} 4$ & & 83Q1 & $81 \mathrm{Q} 3$ & $81 \mathrm{Q} 2$ \\
\hline \multirow{2}{*}{ 1983-1984 } & $P$ & 84Q1 & 83Q4 & & $84 Q^{3}$ & $83 \mathrm{Q} 3$ & & $83 \mathrm{Q} 4$ & & & $83 \mathrm{Q} 4$ & $82 Q^{3}$ \\
\hline & $\mathrm{T}$ & $84 \mathrm{Q} 4$ & $84 \mathrm{Q} 3$ & & & $84 \mathrm{Q} 1$ & & $84 \mathrm{Q} 3$ & $84 \mathrm{Q} 1$ & & & $83 \mathrm{Q} 3$ \\
\hline \multirow{2}{*}{ 1985-1986 } & $\mathrm{P}$ & & $85 \mathrm{Q} 2$ & & & 85Q1 & 85Q3 & 85Q4 & & 85Q3 & & 85Q1 \\
\hline & T & & $85 \mathrm{Q} 4$ & & $86 Q 1$ & $86 Q 4$ & $86 \mathrm{Q} 3$ & $86 \mathrm{Q} 4$ & & $86 \mathrm{Q} 3$ & $85 \mathrm{Q} 4$ & $86 \mathrm{Q} 1$ \\
\hline 1986-1987 & $\begin{array}{l}P \\
T\end{array}$ & 86Q1 & & $\begin{array}{l}86 \mathrm{Q} 1 \\
8703\end{array}$ & & & & & & & $\begin{array}{l}86 \mathrm{Q} 2 \\
8702\end{array}$ & \\
\hline 1987-1988 & $\begin{array}{l}P \\
T\end{array}$ & & 87Q4 & & $\begin{array}{l}87 Q 3 \\
8802\end{array}$ & & & & $\begin{array}{l}87 Q 2 \\
8803\end{array}$ & & & \\
\hline 1988-1989 & $\begin{array}{l}P \\
T\end{array}$ & & & $88 \mathrm{Q3}$ & $88 \mathrm{Q} 4$ & & $88 \mathrm{Q} 4$ & $\begin{array}{l}88 \text { 3 } \\
\text { 89Q1 }\end{array}$ & & $88 \mathrm{Q} 2$ & $\begin{array}{l}89 \mathrm{Q} 1 \\
90 \mathrm{Q} 1\end{array}$ & \\
\hline \multirow{2}{*}{ 1989-1991 } & $P$ & & & & & 90Q3 & & 90Q1 & 89Q1 & & $90 \mathrm{Q} 3$ & 89Q1 \\
\hline & T & 91Q1 & 91Q1 & 90Q4 & & & $91 \mathrm{Q} 2$ & $90 \mathrm{Q} 3$ & & $91 \mathrm{Q} 3$ & 91Q2 & 91Q3 \\
\hline \multirow[b]{2}{*}{ 1991-1994 } & $P$ & 92Q1 & & 91Q4 & & & 91Q4 & 91Q2 & & 92Q1 & $91 \mathrm{Q} 4$ & \\
\hline & $\mathrm{T}$ & 93Q1 & & 93Q2 & 92Q2 & $92 \mathrm{Q} 4$ & 93Q1 & 93Q1 & 92Q4 & 93Q1 & 93Q3 & \\
\hline \multirow{2}{*}{ 1994-1996 } & $P$ & $94 \mathrm{Q} 3$ & 94Q2 & $94 \mathrm{Q} 3$ & 95Q1 & 94Q3 & $94 \mathrm{Q} 4$ & $94 \mathrm{Q} 4$ & $94 Q 4$ & $95 \mathrm{Q} 2$ & $94 \mathrm{Q} 3$ & 95Q1 \\
\hline & $T$ & & $95 \mathrm{Q} 3$ & $95 \mathrm{Q} 4$ & $96 \mathrm{Q} 3$ & $95 \mathrm{Q} 4$ & $96 Q 4$ & $96 \mathrm{Q} 3$ & 95Q4 & $96 \mathrm{Q} 2$ & 95Q2 & 96Q1 \\
\hline \multirow{2}{*}{ 1996-1998 } & $P$ & & 97Q4 & 97Q3 & & 97Q4 & & 97Q3 & & $97 Q 2$ & $96 \mathrm{Q} 2$ & 97Q3 \\
\hline & $\mathrm{T}$ & $96 \mathrm{Q} 3$ & & & & $98 Q 4$ & & $98 Q 4$ & & & $97 \mathrm{Q} 3$ & \\
\hline \multirow{2}{*}{ 1998-1999 } & $P$ & $98 \mathrm{Q} 2$ & & & 98Q4 & & 98Q1 & & & & & \\
\hline & $\mathrm{T}$ & $99 \mathrm{Q} 2$ & 99Q1 & $99 \mathrm{Q} 2$ & 99Q2 & & 99Q1 & & & 99Q1 & & 99Q2 \\
\hline \multirow{2}{*}{ 1999-2002 } & P & 00Q1 & 99Q4 & 00Q1 & 00Q1 & 00Q1 & 99Q4 & 00Q3 & 99Q4 & 00Q1 & $99 \mathrm{Q} 3$ & 00Q3 \\
\hline & $T$ & & $01 \mathrm{Q} 3$ & 01Q1 & $01 \mathrm{Q} 3$ & & $01 \mathrm{Q} 4$ & 01Q3 & $01 \mathrm{Q} 4$ & 01Q3 & O0Q3 & $01 \mathrm{Q} 4$ \\
\hline \multirow{2}{*}{ 2002-2003 } & $P$ & & $02 \mathrm{Q} 3$ & 02Q1 & & & $02 \mathrm{Q} 3$ & $02 Q^{3}$ & & & 01Q1 & \\
\hline & $T$ & 03Q1 & $03 Q^{2}$ & 03Q1 & & $02 Q 1$ & $03 Q^{2}$ & $03 Q^{2}$ & & & $00 \mathrm{Q} 1$ & \\
\hline \multirow{2}{*}{ 2003-2005 } & $P$ & 04Q1 & 04Q1 & $04 \mathrm{Q} 2$ & & & $04 \mathrm{Q} 4$ & 04Q1 & & $04 \mathrm{Q} 2$ & $04 Q_{2}$ & 04Q3 \\
\hline & $\mathrm{T}$ & $04 \mathrm{Q} 4$ & 05Q1 & $04 \mathrm{Q} 4$ & & & $05 Q^{3}$ & $04 \mathrm{Q} 4$ & & $06 \mathrm{Q} 1$ & $04 \mathrm{Q} 4$ & 05Q1 \\
\hline 2005-2007 & $P$ & 06Q3 & 06Q4 & $05 \mathrm{Q} 4$ & 06Q4 & 06Q3 & & 06Q1 & 05Q4 & 06Q4 & 05Q4 & \\
\hline \multirow{2}{*}{ 2007-2009 } & $\frac{1}{P}$ & & & $\begin{array}{l}\text { 07Q1 } \\
08 Q 1\end{array}$ & & & 0702 & & & & $\begin{array}{l}06 \mathrm{Q} 2 \\
07 \mathrm{Q} 3\end{array}$ & 0701 \\
\hline & $\mathrm{T}$ & 09Q1 & 09Q1 & 09Q1 & 09Q1 & $08 \mathrm{Q} 4$ & $08 Q 4$ & 09Q1 & 09Q1 & 09Q1 & 09Q1 & 09Q1 \\
\hline \multicolumn{3}{|l|}{ Coin(+/-1Q) } & $83 \%$ & & $60 \%$ & $54 \%$ & $67 \%$ & $58 \%$ & $57 \%$ & & & \\
\hline \multicolumn{3}{|l|}{ Coin(+1-2Q) } & $92 \%$ & & $64 \%$ & $75 \%$ & $86 \%$ & $61 \%$ & $65 \%$ & & & \\
\hline
\end{tabular}

Last two lines show the coincidence of our indicators' turning points with the turning points reported by ECRI allowing for $+1-1$ (bold) or 2 (red) quarters of discrepancy 
Table A2-1. Growth rate cycle turning points. Full sample: 1971Q1-2010Q4. Durations of the cycles

\begin{tabular}{|c|c|c|c|c|c|}
\hline \multicolumn{6}{|c|}{ COMMON INDICATOR } \\
\hline Peaks & Troughs & $\begin{array}{l}\text { Peak-to- } \\
\text { Peak }\end{array}$ & $\begin{array}{c}\text { Trough-to- } \\
\text { Peak }\end{array}$ & $\begin{array}{c}\text { Trough-to- } \\
\text { Trough }\end{array}$ & $\begin{array}{l}\text { Peak-to- } \\
\text { Trough }\end{array}$ \\
\hline 1972:04 & 1974:03 & & & & 7 \\
\hline 1976:02 & 1977:02 & 14 & 7 & 11 & 4 \\
\hline 1979:01 & 1980:04 & 11 & 7 & 14 & 7 \\
\hline 1982:03 & 1983:01 & 14 & 7 & 9 & 2 \\
\hline 1984:01 & 1984:04 & 6 & 4 & 7 & 3 \\
\hline 1986:01 & 1991:01 & 8 & 5 & 25 & 20 \\
\hline 1992:01 & 1993:01 & 24 & 4 & 8 & 4 \\
\hline 1994:03 & 1996:03 & 10 & 6 & 14 & 8 \\
\hline 1998:02 & 1999:02 & 15 & 7 & 11 & 4 \\
\hline 2000:01 & 2003:01 & 7 & 3 & 15 & 12 \\
\hline 2004:01 & 2004:04 & 16 & 4 & 7 & 3 \\
\hline 2006:03 & 2009:01 & 10 & 7 & 17 & 10 \\
\hline \multicolumn{6}{|c|}{ UNITED KINGDOM } \\
\hline Peaks & Troughs & $\begin{array}{l}\text { Peak-to- } \\
\text { Peak }\end{array}$ & $\begin{array}{c}\text { Trough-to- } \\
\text { Peak }\end{array}$ & $\begin{array}{c}\text { Trough-to- } \\
\text { Trough } \\
\end{array}$ & $\begin{array}{c}\text { Peak-to- } \\
\text { Trough }\end{array}$ \\
\hline & 1971:03 & & & & \\
\hline 1972:04 & 1973:04 & & 5 & 9 & 4 \\
\hline 1974:04 & 1975:02 & 8 & 4 & 6 & 2 \\
\hline 1976:03 & $1977: 03$ & 7 & 5 & 9 & 4 \\
\hline 1979:01 & 1980:04 & 10 & 6 & 13 & 7 \\
\hline 1983:04 & $1984: 03$ & 19 & 12 & 15 & 3 \\
\hline 1985:02 & 1985:04 & 6 & 3 & 5 & 2 \\
\hline 1987:04 & 1991:01 & 10 & 8 & 21 & 13 \\
\hline 1994:02 & 1995:03 & 26 & 13 & 18 & 5 \\
\hline 1997:04 & 1999:01 & 14 & 9 & 14 & 5 \\
\hline 1999:04 & 2001:03 & 8 & 3 & 10 & 7 \\
\hline 2002:03 & 2003:02 & 11 & 4 & 7 & 3 \\
\hline 2004:01 & 2005:01 & 6 & 3 & 7 & 4 \\
\hline 2006:04 & 2009:01 & 11 & 7 & 16 & 9 \\
\hline \multicolumn{6}{|c|}{ DENMARK } \\
\hline Peaks & Troughs & $\begin{array}{l}\text { Peak-to- } \\
\text { Peak }\end{array}$ & $\begin{array}{c}\text { Trough-to- } \\
\text { Peak }\end{array}$ & $\begin{array}{c}\text { Trough-to- } \\
\text { Trough }\end{array}$ & $\begin{array}{l}\text { Peak-to- } \\
\text { Trough }\end{array}$ \\
\hline 1972:04 & 1974:03 & & & & 7 \\
\hline 1976:01 & 1977:01 & 13 & 6 & 10 & 4 \\
\hline 1979:02 & 1980:04 & 13 & 9 & 15 & 6 \\
\hline 1982:03 & 1983:01 & 13 & 7 & 9 & 2 \\
\hline 1986:01 & $1987: 03$ & 14 & 12 & 18 & 6 \\
\hline 1988:03 & 1990:04 & 10 & 4 & 13 & 9 \\
\hline 1991:04 & 1993:02 & 13 & 4 & 10 & 6 \\
\hline 1994:03 & $1995: 04$ & 11 & 5 & 10 & 5 \\
\hline 1997:03 & 1999:02 & 12 & 7 & 14 & 7 \\
\hline 2000:01 & 2001:01 & 10 & 3 & 7 & 4 \\
\hline 2002:01 & 2003:01 & 8 & 4 & 8 & 4 \\
\hline 2004:02 & 2004:04 & 9 & 5 & 7 & 2 \\
\hline 2005:04 & 2007:01 & 6 & 4 & 9 & 5 \\
\hline 2008:01 & 2009:01 & 9 & 4 & 8 & 4 \\
\hline
\end{tabular}




\begin{tabular}{|c|c|c|c|c|c|}
\hline \multicolumn{6}{|c|}{ ITALY } \\
\hline Peaks & Troughs & $\begin{array}{l}\text { Peak-to- } \\
\text { Peak }\end{array}$ & $\begin{array}{c}\text { Trough-to- } \\
\text { Peak }\end{array}$ & $\begin{array}{c}\text { Trough-to- } \\
\text { Trough }\end{array}$ & $\begin{array}{c}\text { Peak-to- } \\
\text { Trough }\end{array}$ \\
\hline & 1972:01 & & & & \\
\hline 1973:04 & 1975:01 & & 7 & 12 & 5 \\
\hline 1976:02 & $1977: 03$ & 10 & 5 & 10 & 5 \\
\hline 1979:04 & 1982:04 & 14 & 9 & 21 & 12 \\
\hline 1983:04 & 1984:03 & 16 & 4 & 7 & 3 \\
\hline 1985:04 & 1986:04 & 8 & 5 & 9 & 4 \\
\hline 1988:03 & 1989:01 & 11 & 7 & 9 & 2 \\
\hline 1990:01 & 1990:03 & 6 & 4 & 6 & 2 \\
\hline 1991:02 & 1993:01 & 5 & 3 & 10 & 7 \\
\hline 1994:04 & 1996:03 & 14 & 7 & 14 & 7 \\
\hline $1997: 03$ & 1998:04 & 11 & 4 & 9 & 5 \\
\hline 2000:03 & 2001:03 & 12 & 7 & 11 & 4 \\
\hline 2002:03 & 2003:02 & 8 & 4 & 7 & 3 \\
\hline 2004:01 & 2004:04 & 6 & 3 & 6 & 3 \\
\hline 2006:01 & 2009:01 & 8 & 5 & 17 & 12 \\
\hline \multicolumn{6}{|c|}{ NETHERLANDS } \\
\hline \multirow[t]{2}{*}{ Peaks } & Troughs & $\begin{array}{c}\text { Peak-to- } \\
\text { Peak }\end{array}$ & $\begin{array}{c}\text { Trough-to- } \\
\text { Peak } \\
\end{array}$ & $\begin{array}{c}\text { Trough-to- } \\
\text { Trough }\end{array}$ & $\begin{array}{c}\text { Peak-to- } \\
\text { Trough } \\
\end{array}$ \\
\hline & 1971:03 & & & & \\
\hline 1973:03 & 1975:02 & & 8 & 15 & 7 \\
\hline 1976:02 & $1977: 02$ & 11 & 4 & 8 & 4 \\
\hline 1978:02 & 1978:04 & 8 & 4 & 6 & 2 \\
\hline 1979:04 & $1981: 03$ & 6 & 4 & 11 & 7 \\
\hline 1983:04 & 1985:04 & 16 & 9 & 17 & 8 \\
\hline 1986:02 & $1987: 02$ & 10 & 2 & 6 & 4 \\
\hline 1989:01 & 1990:01 & 11 & 7 & 11 & 4 \\
\hline 1990:03 & 1991:02 & 6 & 2 & 5 & 3 \\
\hline 1991:04 & 1993:03 & 5 & 2 & 9 & 7 \\
\hline 1994:03 & 1995:02 & 11 & 4 & 7 & 3 \\
\hline 1996:02 & $1997: 03$ & 7 & 4 & 9 & 5 \\
\hline 1999:03 & $2000: 03$ & 13 & 8 & 12 & 4 \\
\hline 2001:01 & 2003:01 & 6 & 2 & 10 & 8 \\
\hline 2004:02 & 2004:04 & 13 & 5 & 7 & 2 \\
\hline 2005:04 & 2006:02 & 6 & 4 & 6 & 2 \\
\hline 2007:03 & 2009:01 & 7 & 5 & 11 & 6 \\
\hline \multicolumn{6}{|c|}{ SWEDEN } \\
\hline Peaks & Troughs & $\begin{array}{c}\text { Peak-to- } \\
\text { Peak } \\
\end{array}$ & $\begin{array}{c}\text { Trough-to- } \\
\text { Peak }\end{array}$ & $\begin{array}{c}\text { Trough-to- } \\
\text { Trough }\end{array}$ & $\begin{array}{c}\text { Peak-to- } \\
\text { Trough }\end{array}$ \\
\hline 1974:01 & $1977: 03$ & & & & 14 \\
\hline 1979:02 & 1981:02 & 21 & 7 & 15 & 8 \\
\hline 1982:01 & 1983:01 & 11 & 3 & 7 & 4 \\
\hline $1984: 03$ & 1986:01 & 10 & 6 & 12 & 6 \\
\hline $1987: 03$ & 1988:02 & 12 & 6 & 9 & 3 \\
\hline 1988:04 & 1992:04 & 5 & 2 & 18 & 16 \\
\hline 1995:01 & 1996:03 & 25 & 9 & 15 & 6 \\
\hline 1998:04 & 1999:02 & 15 & 9 & 11 & 2 \\
\hline 2000:01 & 2001:03 & 5 & 3 & 9 & 6 \\
\hline 2006:04 & 2009:01 & 27 & 21 & 30 & 9 \\
\hline \multicolumn{6}{|c|}{ GERMANY } \\
\hline Peaks & Troughs & $\begin{array}{l}\text { Peak-to- } \\
\text { Peak }\end{array}$ & $\begin{array}{l}\text { Trough-to- } \\
\text { Peak }\end{array}$ & $\begin{array}{c}\text { Trough-to- } \\
\text { Trough }\end{array}$ & $\begin{array}{l}\text { Peak-to- } \\
\text { Trough }\end{array}$ \\
\hline & 1971:03 & & & & \\
\hline 1972:04 & 1975:01 & & 5 & 14 & 9 \\
\hline 1976:01 & $1977: 04$ & 13 & 4 & 11 & 7 \\
\hline 1979:04 & 1980:04 & 15 & 8 & 12 & 4 \\
\hline 1981:02 & 1982:02 & 6 & 2 & 6 & 4 \\
\hline 1983:03 & 1984:01 & 9 & 5 & 7 & 2 \\
\hline 1985:01 & 1986:04 & 6 & 4 & 11 & 7 \\
\hline 1990:03 & 1992:04 & 22 & 15 & 24 & 9 \\
\hline 1994:03 & 1995:04 & 16 & 7 & 12 & 5 \\
\hline 1997:04 & 1998:04 & 13 & 8 & 12 & 4 \\
\hline 2000:01 & 2002:01 & 9 & 5 & 13 & 8 \\
\hline $2006: 03$ & 2008:04 & 26 & 18 & 27 & 9 \\
\hline
\end{tabular}




\begin{tabular}{|c|c|c|c|c|c|}
\hline \multicolumn{6}{|c|}{ FRANCE } \\
\hline Peaks & Troughs & $\begin{array}{c}\text { Peak-to- } \\
\text { Peak }\end{array}$ & $\begin{array}{c}\text { Trough-to- } \\
\text { Peak }\end{array}$ & $\begin{array}{c}\text { Trough-to- } \\
\text { Trough }\end{array}$ & $\begin{array}{c}\text { Peak-to- } \\
\text { Trough }\end{array}$ \\
\hline 1973:01 & $1975: 02$ & & & & 9 \\
\hline 1976:02 & $1977: 03$ & 13 & 4 & 9 & 5 \\
\hline 1978:03 & 1980:04 & 9 & 4 & 13 & 9 \\
\hline $1982: 01$ & 1983:01 & 14 & 5 & 9 & 4 \\
\hline $1985: 03$ & 1986:03 & 14 & 10 & 14 & 4 \\
\hline 1988:04 & 1991:02 & 13 & 9 & 19 & 10 \\
\hline 1991:04 & 1993:01 & 12 & 2 & 7 & 5 \\
\hline 1994:04 & 1996:04 & 12 & 7 & 15 & 8 \\
\hline 1998:01 & 1999:01 & 13 & 5 & 9 & 4 \\
\hline 1999:04 & 2001:04 & 7 & 3 & 11 & 8 \\
\hline $2002: 03$ & 2003:02 & 11 & 3 & 6 & 3 \\
\hline 2004:04 & $2005: 03$ & 9 & 6 & 9 & 3 \\
\hline 2007:02 & 2008:04 & 10 & 7 & 13 & 6 \\
\hline \multicolumn{6}{|c|}{ SPAIN } \\
\hline Peaks & Troughs & $\begin{array}{c}\text { Peak-to- } \\
\text { Peak } \\
\end{array}$ & $\begin{array}{c}\text { Trough-to- } \\
\text { Peak } \\
\end{array}$ & $\begin{array}{c}\text { Trough-to- } \\
\text { Trough }\end{array}$ & $\begin{array}{c}\text { Peak-to- } \\
\text { Trough }\end{array}$ \\
\hline 1972:01 & 1975:02 & & & & 13 \\
\hline 1976:03 & 1978:04 & 18 & 5 & 14 & 9 \\
\hline 1979:04 & 1980:04 & 13 & 4 & 8 & 4 \\
\hline 1982:04 & 1984:01 & 12 & 8 & 13 & 5 \\
\hline $1987: 02$ & $1988: 03$ & 18 & 13 & 18 & 5 \\
\hline 1989:01 & 1992:04 & 7 & 2 & 17 & 15 \\
\hline 1994:04 & $1995: 04$ & 23 & 8 & 12 & 4 \\
\hline 1999:04 & 2001:04 & 20 & 16 & 24 & 8 \\
\hline 2005:04 & 2009:01 & 24 & 16 & 29 & 13 \\
\hline \multicolumn{6}{|c|}{ BELGIUM } \\
\hline Peaks & Troughs & $\begin{array}{c}\text { Peak-to- } \\
\text { Peak }\end{array}$ & $\begin{array}{c}\text { Trough-to- } \\
\text { Peak }\end{array}$ & $\begin{array}{c}\text { Trough-to- } \\
\text { Trough }\end{array}$ & $\begin{array}{c}\text { Peak-to- } \\
\text { Trough }\end{array}$ \\
\hline 1973:02 & $1975: 02$ & & & & 8 \\
\hline 1976:02 & 1977:02 & 12 & 4 & 8 & 4 \\
\hline 1979:04 & 1981:02 & 14 & 10 & 16 & 6 \\
\hline $1982: 02$ & 1983:01 & 10 & 4 & 7 & 3 \\
\hline $1985: 03$ & 1986:03 & 13 & 10 & 14 & 4 \\
\hline 1988:02 & 1991:03 & 11 & 7 & 20 & 13 \\
\hline $1992: 01$ & 1993:01 & 15 & 2 & 6 & 4 \\
\hline 1995:02 & 1996:02 & 13 & 9 & 13 & 4 \\
\hline $1997: 02$ & 1999:01 & 8 & 4 & 11 & 7 \\
\hline 2000:01 & 2001:03 & 11 & 4 & 10 & 6 \\
\hline 2004:02 & 2006:01 & 17 & 11 & 18 & 7 \\
\hline 2006:04 & 2009:01 & 10 & 3 & 12 & 9 \\
\hline \multicolumn{6}{|c|}{ FINLAND } \\
\hline Peaks & Troughs & $\begin{array}{c}\text { Peak-to- } \\
\text { Peak }\end{array}$ & $\begin{array}{c}\text { Trough-to- } \\
\text { Peak }\end{array}$ & $\begin{array}{c}\text { Trough-to- } \\
\text { Trough }\end{array}$ & $\begin{array}{c}\text { Peak-to- } \\
\text { Trough }\end{array}$ \\
\hline & 1971:03 & & & & \\
\hline 1973:02 & $1975: 02$ & & 7 & 15 & 8 \\
\hline 1976:02 & 1977:03 & 12 & 4 & 9 & 5 \\
\hline 1980:02 & 1981:02 & 16 & 11 & 15 & 4 \\
\hline $1982: 03$ & 1983:03 & 9 & 5 & 9 & 4 \\
\hline 1985:01 & 1986:01 & 10 & 6 & 10 & 4 \\
\hline 1989:01 & 1991:03 & 16 & 12 & 22 & 10 \\
\hline 1995:01 & 1996:01 & 24 & 14 & 18 & 4 \\
\hline $1997: 03$ & 1999:02 & 10 & 6 & 13 & 7 \\
\hline $2000: 03$ & 2001:04 & 12 & 5 & 10 & 5 \\
\hline $2004: 03$ & 2005:01 & 16 & 11 & 13 & 2 \\
\hline 2007:01 & 2009:01 & 10 & 8 & 16 & 8 \\
\hline
\end{tabular}


Table A3. Test for multiple unknown structural breaks

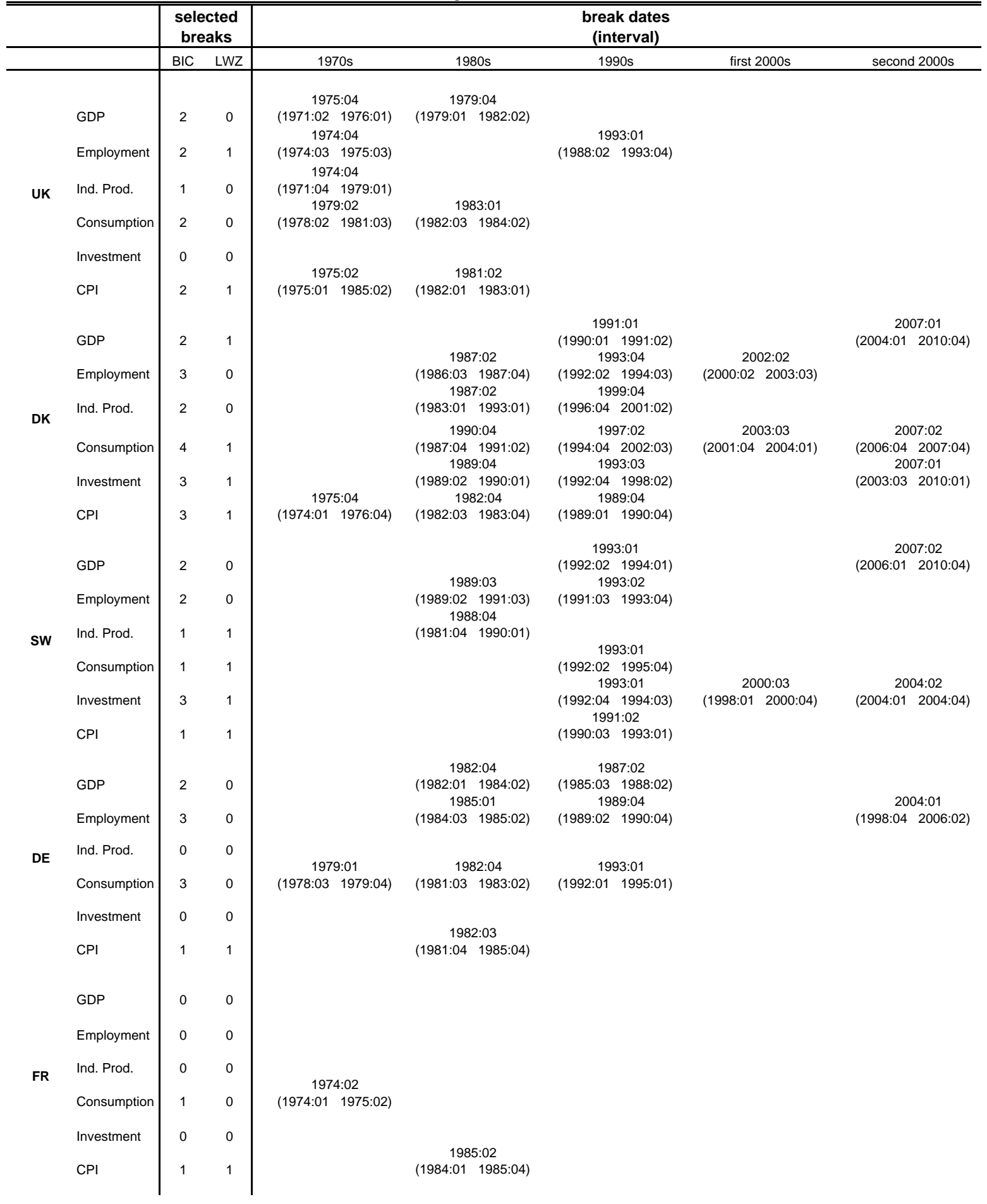




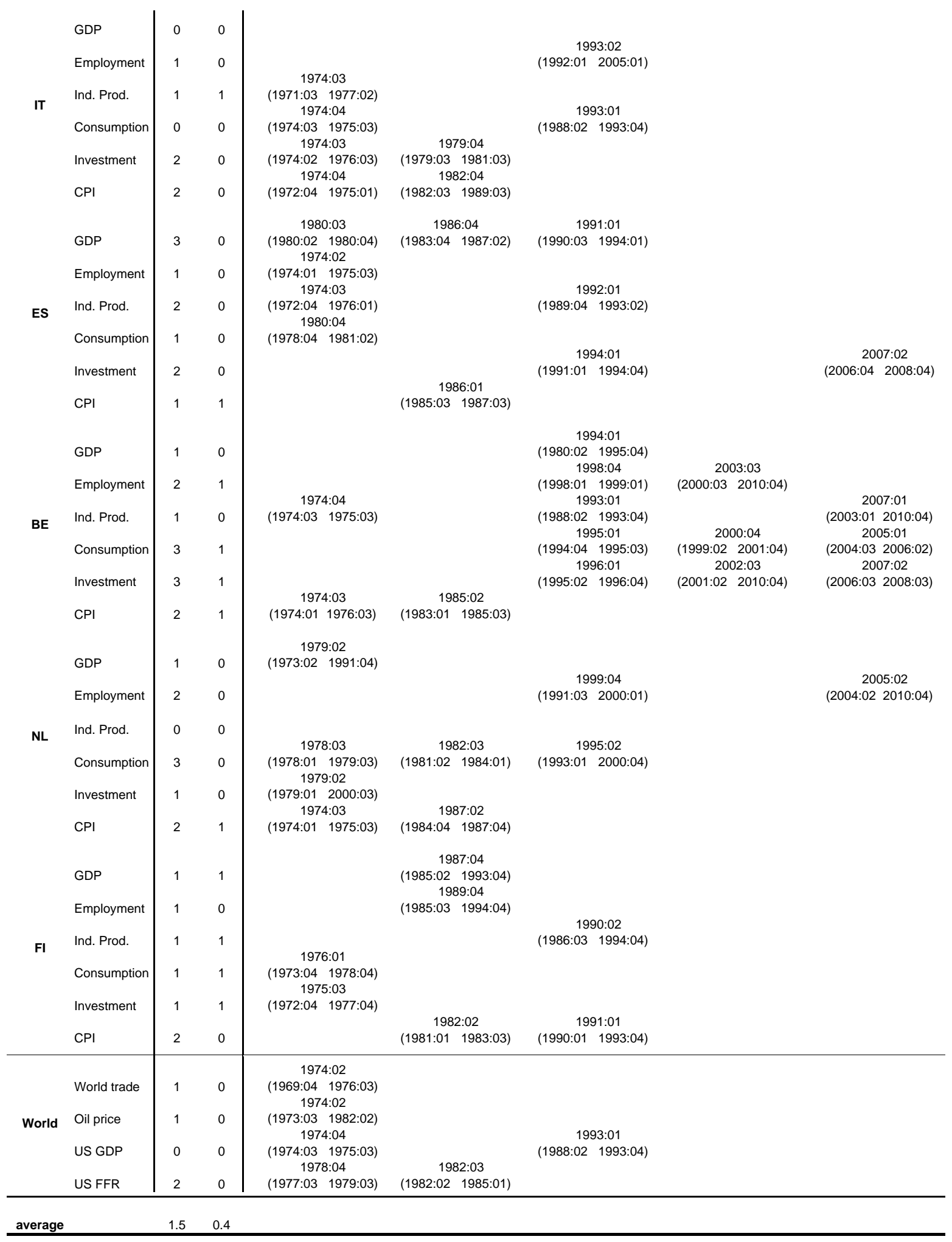

Tests are based on the procedure by Bai and Perron, JOURNAL OF APPLIED ECONOMETRICS 18: 1-22 (2003). BIC: Bayesian Information Criterion; LWZ: modified Schwarz criterion 
Figure 5a. Out-of-Sample forecast of GDP growth - 1992:1

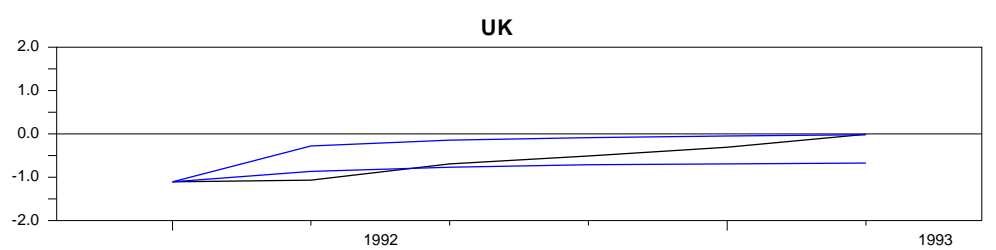

DENMARK
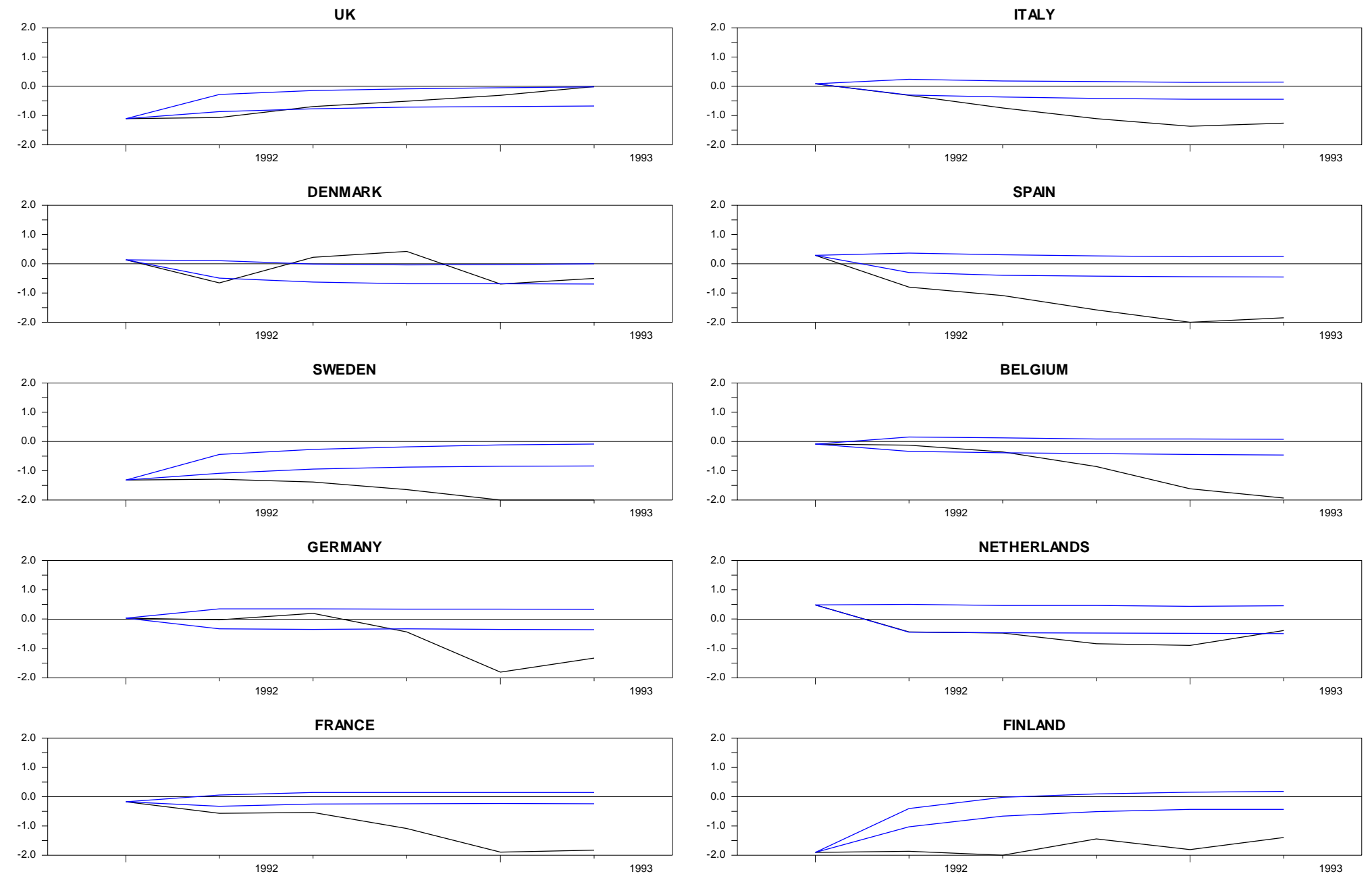
Figure 6a. Responses of GDP growth to one standard error increase in German real activity
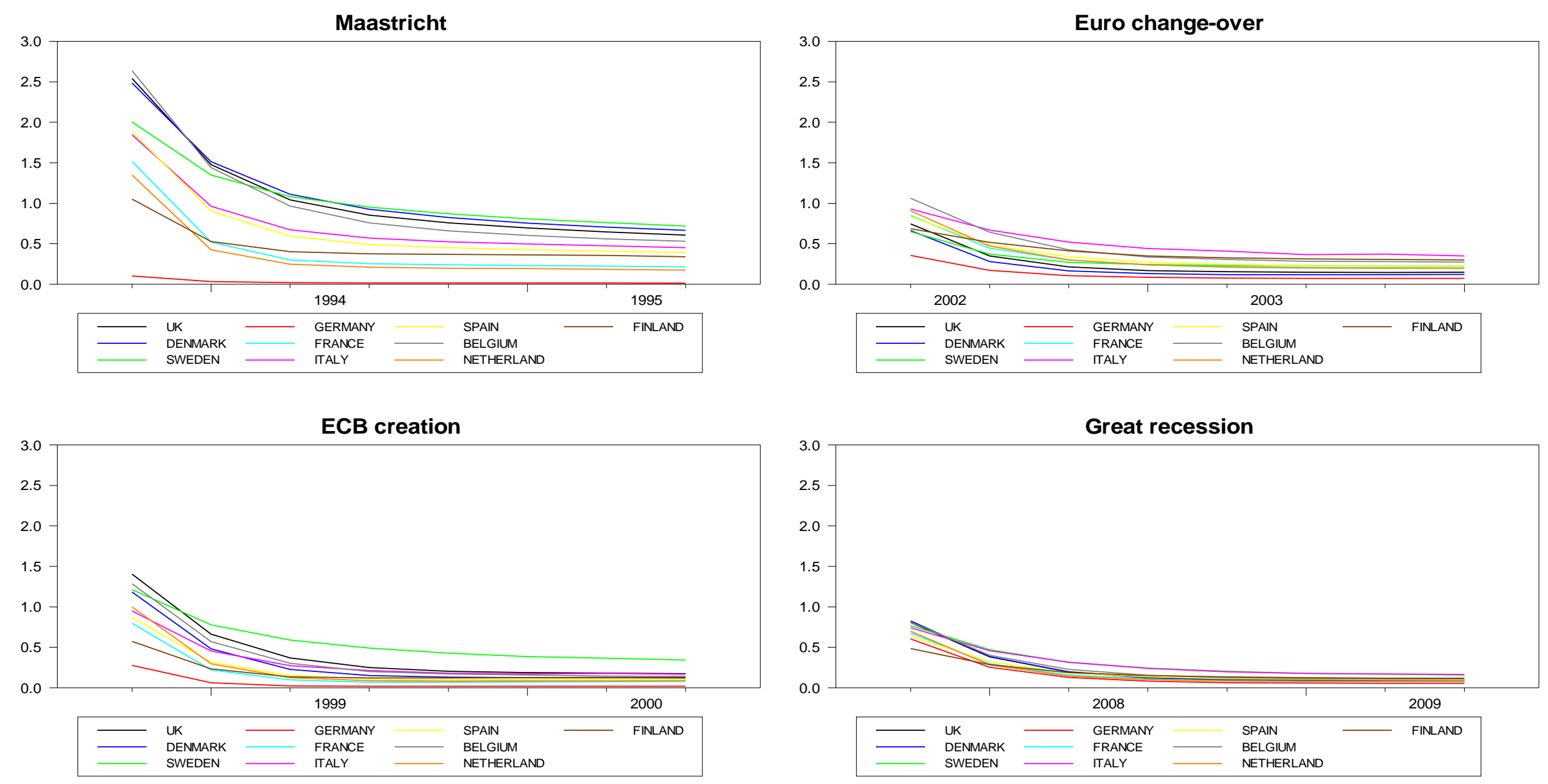
Figure 7a. Responses of GDP growth to one standard error increase in US GDP growth
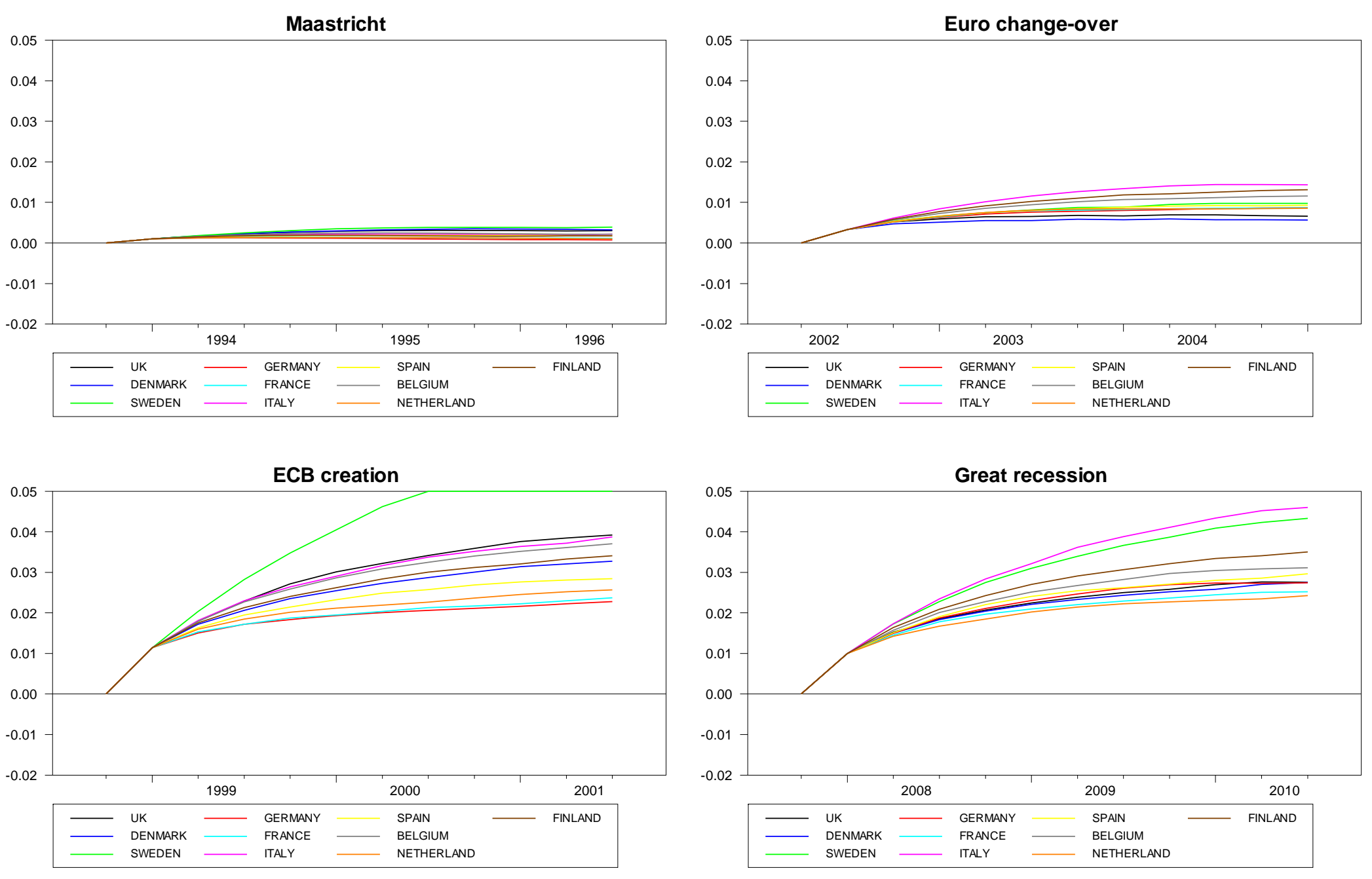